\title{
ASSOCIATIONS BETWEEN ALCOHOL CONSUMPTION AND FASTING BLOOD GLUCOSE IN YOUNG ADULTS
}

\author{
A Thesis \\ presented to \\ the Faculty of California Polytechnic State University, \\ San Luis Obispo
}

\author{
In Partial Fulfillment \\ of the Requirements for the Degree \\ Master of Science in Agriculture
}

by

Julie Lucca

May 31, 2013 
(C) 2013

Julie Lucca

\section{ALL RIGHTS RESERVED}

Page | ii 


\section{COMMITTEE MEMBERSHIP}

TITLE:

AUTHOR:

DATE SUBMITTED:

COMMITTEE CHAIR:

COMMITTEE MEMBER:

COMMITTEE MEMBER:
Associations Between Alcohol Consumption and Fasting Blood Glucose in Young Adults

Julie Lucca

May 31, 2013

Dr. Aydin Nazmi, Assistant Professor Food Science and Nutrition Department

Dr. Suzanne Phelan, Associate Professor Kinesiology Department

Professor Veronika Lesiuk

Kinesiology Department 


\begin{abstract}
Associations Between Alcohol Consumption and Fasting Blood Glucose in Young Adults Julie Lucca
\end{abstract}

Current research shows moderate alcohol consumption is associated with decreased risk of diabetes and excessive consumption or binge drinking can cause insulin resistance and diabetes. In 2010, diabetes was the seventh leading cause of death in the United States and was responsible for significant health complications: blindness, kidney failure, and limb amputations, and is a large national economic burden. Fasting blood glucose (FBG) is a tool used to help diagnose diabetes. Abnormally high FBG, $\geq 100 \mathrm{mg} / \mathrm{dl}$, is indicative of diabetes and pre-diabetes. Few studies have observed diabetic prevalence among young adults or college students. Studying young adults can help provide added information about early risk factors for diabetes and pre-diabetes, facilitating public health efforts to stem the rising tide of the diabetes epidemic. This study aimed to research the associations between alcohol consumption (numbers of days alcohol consumed in the past month and binge alcohol consumption in the past month) and FBG in a college population as part of the FLASH cohort study. FBG levels were measured in 141 young adult participants and alcohol consumption was determined by self report. Other individual-level characteristics and potential confounding variables were also collected. The association between alcohol consumption and FBG followed a J-shaped curve whereby students who reported drinking 6-8 days within the last 30 days showed significantly lower FBG levels than those who did not drink and those who consumed alcohol on nine or more days $(\mathrm{p}=0.04)$. Binge drinking did not have a significant association with FBG ( $p=0.4)$. Sex and body mass index were also significantly associated with FBG. In conclusion, moderate frequency of alcohol consumption is found to have an inverse relationship with FBG and excessive drinking can reverse these effects.

Keywords: Alcohol, diabetes, fasting blood glucose, 


\section{ACKNOWLEDGMENTS}

Thank you to the principle investigators, Dr. Ann Yelmokas McDermott PhD, MS, LDN and Dr. Nazmi PhD for developing this study. And thank you to the Maxwell Family, Cal Poly Kinesiology Department's STRIDE program, Cal Poly College of Science and Math, and the CSU Extramural Funding Initiative for providing funding for the research.

I would like to thank my committee Dr. Phelan, Professor Lesiuk, and Dr. Nazmi for your time and hard work in me and this project. Dr Phelan I value your background and expertise in diabetes. Professor Lesiuk, I am incredibly grateful for your exhausting efforts of data entry and coding. Dr. Nazmi, I especially thank you for taking me under your wing and teaching me to see beyond molecules and how they impact populations and communities. Thank you for identifying and acknowledging my passion for nutrition and healthcare and taking me on as your graduate student.

Thank you to all the Heart Health Laboratory research assistants and STRIDE Assessment Team (A-TEAM). Thank you for your time and effort calling, scheduling, waking up early, and finger pricking all our 141 participants. Without you, none of this would have been possible.

Alex, you have more faith in me than I ever had for myself. Your confidence in me kept pushing me forward.

Mom, thank you for your constant support throughout my entire graduate career. I love you very much.

Most of all, I credit all my work and effort to God, who without him, I could not have accomplished this. 


\section{TABLE OF CONTENTS}

LIST OF TABLES viii

LIST OF FIGURES viiix

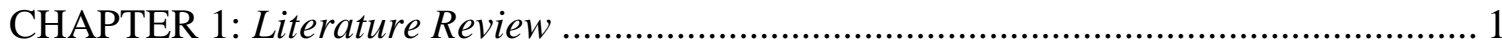

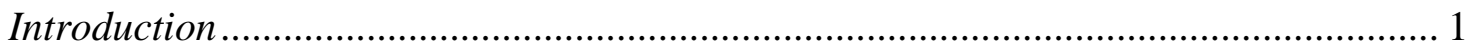

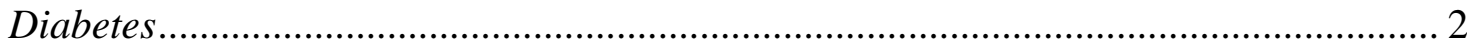

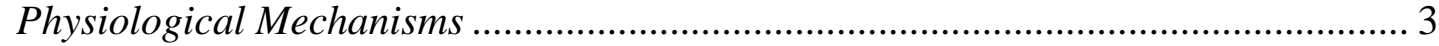

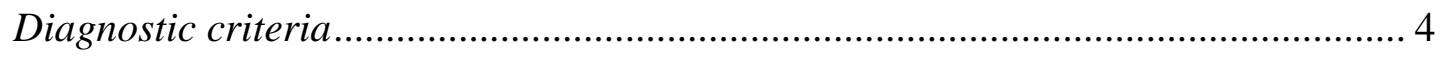

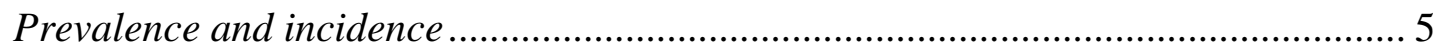

Demographic risk factors of diabetes................................................................... 8

Genetic physiological, and behavioral risk factors of diabetes ............................... 10

_ Genetic risk factors .......................................................................................... 10

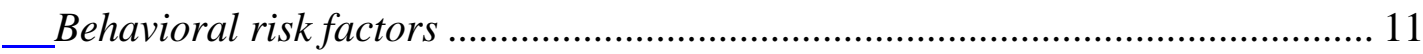

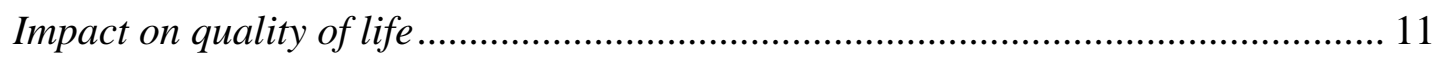

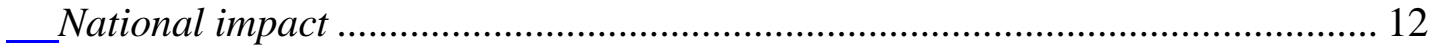

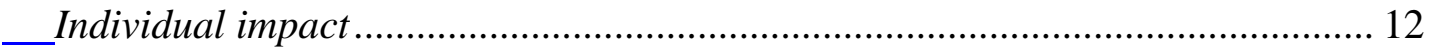

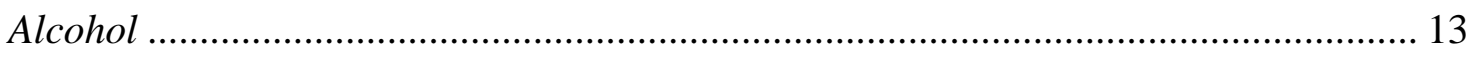

Components and mechanism ............................................................................. 13

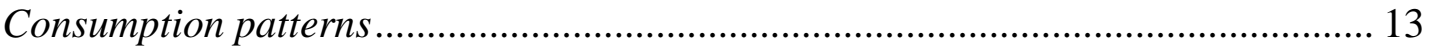

Definitions of alcohol measurements ................................................................ 15

Alcohol consumption and binge drinking ................................................................ 16

Epidemiology of consumption among young adults .............................................. 17

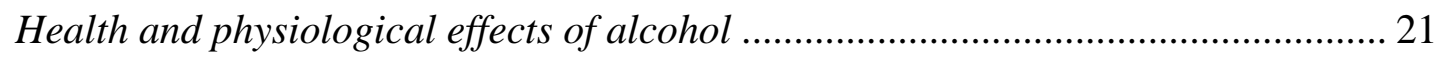

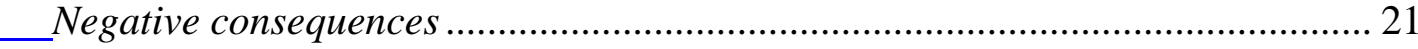

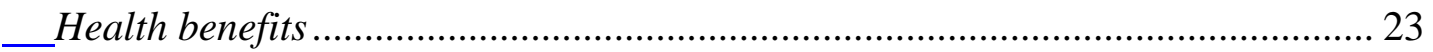

Alcohol and fasting blood glucose and diabetes mellitus......................................... 26

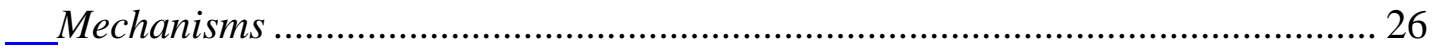

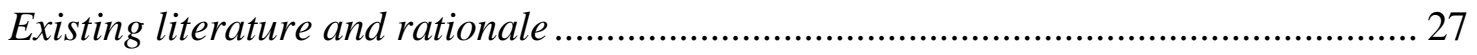

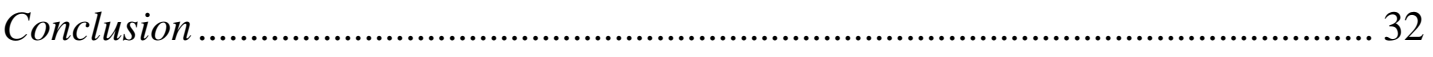

CHAPTER 2: Methods and Materials .......................................................................... 33

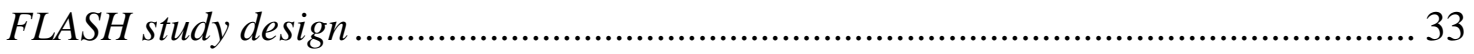




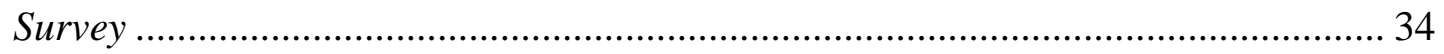

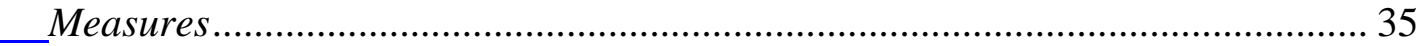

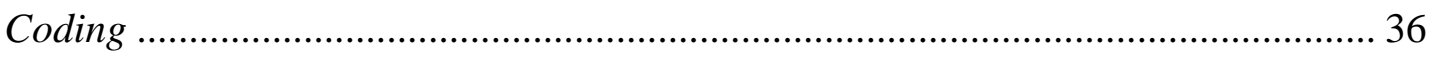

Procedure for fasting blood glucose sampling ..................................................... 39

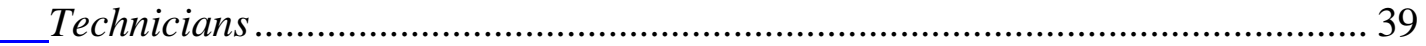

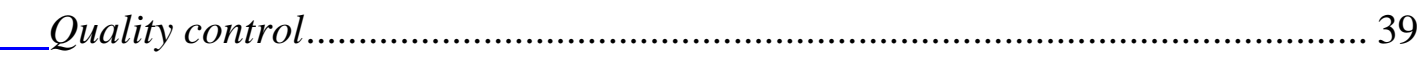

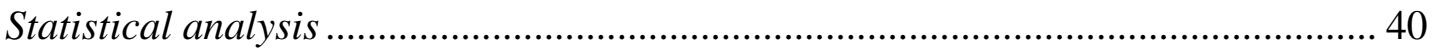

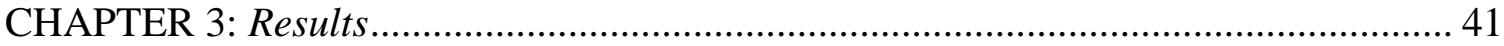

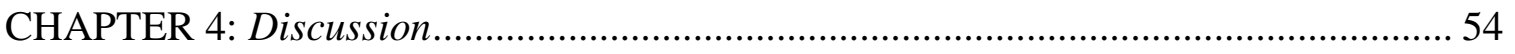

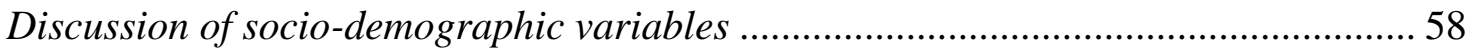

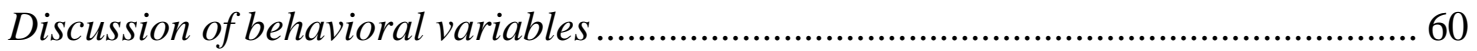

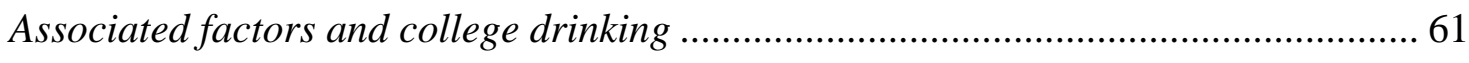

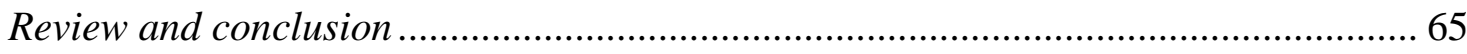

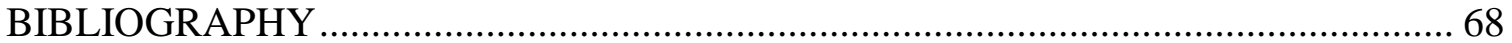




\section{LIST OF TABLES}

Page

Table 1 American Diabetes Association diagnosis criteria of fasting blood glucose for diabetes.

Table 2. Percent (SD) of descriptive socio-demographics prevalence of alcohol consumption 15

Table 3. Definitions of light, moderate, and heavy drinking habits from results 17

Table 4. Case control analysis of alcohol consumption and relative risk of coronary heart disease 25

Table 5. Dates of research fieldwork for each phase of the FLASH study (2009-2012). 34

Table 6. Sections of the online FLASH survey .......................................................... 34

Table 7. Survey questions regarding alcohol consumption ......................................... 36

Table 8. Percent or mean (SD) of descriptive socio-demographics $(n=141) \ldots \ldots \ldots \ldots \ldots \ldots . . . . . . . .41$

Table 9. Percent or mean (SD) of behavioral and anthropometric variables 42

Table 10. Percent frequency of alcohol consumption according to socio-demographic variables and behavioral patterns in past 30 days Error! Bookmark not defined. Table 11. Frequency of binge drinking during one sitting according to sociodemographic variables and behavioral patterns in past 30 days .................................. 46

Table 12. Fasting blood glucose by socio-demographic characteristics ........................ 47

Table 13. Fasting blood glucose according to behavioral patterns ............................... 48

Table 14. Fasting blood glucose and frequency of drinking within last 30 days............. 48

Table 15. Fasting blood glucose and binge drinking within last 30 days ....................... 49

Table 16. Unadjusted and four sequentially adjusted linear regression models beta (95\% CI) for associations with fasting blood glucose $(\mathrm{mg} / \mathrm{dl})$, with the number of days alcohol consumed as the primary exposure variable.

Table 17. Unadjusted and four sequentially adjusted linear regression models beta (95\% CI) for associations with fasting blood glucose $(\mathrm{mg} / \mathrm{dl})$, with the number of days of binge drinking as the primary exposure variable. 


\section{LIST OF FIGURES}

Page

Figure 1. Annual number of new cases of adult (18-79 years) diagnosed with

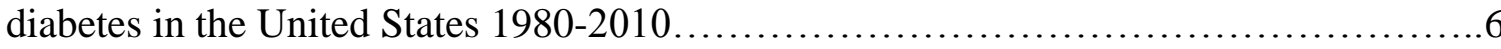

Figure 2. Incidence of diagnosed diabetes by age group per 1,000 population aged

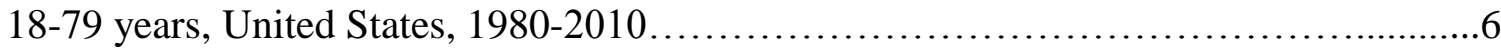

Figure 3. Prevalence of diagnosed diabetes among US adults in 1991 and $2001 \ldots \ldots . . .7$

Figure 4. NIAAA standards for one alcoholic drink............................. 16

Figure 5. Prevalence of alcohol use from 30 day surveys of college students and non-college young adults aged 19-22 from 1980-2009..........................19

Figure 6. Prevalence of binge drinking from past two week surveys of college students and non-college young adults aged 19-22 from 1980-2009...

Figure 7. Prevalence of binge drinking episodes from past two week surveys of college students and non-college young adults by sex beginning 4th year of high school through first three years of college.

Figure 8. Reaction cascades of inflammatory cytokines and insulin on glycogen synthesis

Figure 9. Meta-analysis of twenty studies examining relative risk of diabetes and alcohol consumption in grams per day

Figure 10. Frequency of heavy episodic drinking in the past two weeks among students by Greek involvement. 


\section{CHAPTER 1}

\section{Literature Review}

\section{Introduction}

Diabetes mellitus is a metabolic disorder whereby glucose cannot effectively get transported out of the blood. The hormone insulin facilitates glucose from the blood and into tissues, decreasing blood sugar concentration. In diabetics, insulin is not produced either in adequate amounts or the body cannot effectively respond to insulin produced. Chronically high blood glucose concentration can cause damage to capillaries, inhibiting the efficiency of blood circulation. This can lead to severe ailments such as kidney disease, limb amputations, glaucoma, and bacterial infection (CDC, 2011a; Marieb and Hoehn, 2011; Mirsky, Stanley, Rattner, Heilman, \& Mirsky, 2006).

Fasting blood glucose (FBG) assessment is a tool used to help diagnose diabetes where glucose concentration is measured using venous or capillary blood. After a period of fasting, a healthy individual would exhibit a glucose concentration, between 70-100 $\mathrm{mg} / \mathrm{dl}$. However, even after a period of fasting, a diabetic would exhibit an abnormally high concentration of glucose in the blood, $(126+\mathrm{mg} / \mathrm{dl})$ providing evidence for diabetes (CDC, 2011a).

Alcohol consumption has been shown to reduce the risk of developing type II diabetes by facilitating the concentration of the protein adiponectin (Sierksma et al., 2004; Beulens et al., 2007; Joosten, Beulens, Kersten, \& Hendriks, 2008). Adiponectin has been shown to increase insulin receptor substrate in the liver and aid in transporting glucose out of the blood (Sierksma et al., 2004; Awazawa et al., 2011), however, excessive alcohol consumption has been shown to decrease insulin sensitivity and 
increase the risk of type II diabetes (Baliunas et al., 2009; Joosten et al., 2008; Beulens et al., 2007; Facchini, Chen, \& Reaven, 1994; Davies et al., 2002).

Many studies have observed alcohol's effects on diabetes and fasting blood glucose, yet few have examined young adults. The objective of this study was to examine the associations between alcohol consumption and fasting blood glucose concentration in college students. Studying risk factors and early detection can aid in the reversal or delay of diabetes, which can facilitate public health efforts to stem the rising tide of the diabetes epidemic and increase quality of life.

\section{Diabetes}

Insulin is a polypeptide hormone secreted by the beta cells of the pancreas, which is responsible for regulating energy and metabolism (Marieb and Hoehn, 2011; Rosenthal and Glew, 2009; Gropper, S. A. S., Groff J. L., \& Smith, J. L. 2009; Nathan et al., 2007). Glucose is the body's main source of energy and fuel and required by all cells to maintain function. Insulin is released when blood glucose is high (after a meal) to facilitate glucose transport into tissues, and to promote glucose storage. After a high carbohydrate meal, it may take a healthy person about 2-3 hours for insulin to return blood glucose levels to fasting levels of less than $100 \mathrm{mg} / \mathrm{ml}$ blood (Rostenthal and Glew, 2009; Mirsky et al., 2006). Type II diabetes is caused by the inability to produce functional insulin or the inability for insulin to be recognized at the tissue layer (Gropper et al., 2009). Chronically high blood glucose levels resulting from poor diet, inactivity, genetic predisposition, or other factors, can overwhelm the pancreas over time and inhibit the ability to produce functional insulin at normal concentrations. Therefore, more insulin is required to facilitate glucose transport, raising the concentration of insulin required to be functional. 
Chronically high insulin concentrations can cause insulin insensitivity which can keep excess glucose in the blood for extended periods of time (Marieb and Hoehn, 2011; Gropper et al., 2009; Mirsky et al., 2006; Dunstan et al., 2002; Nathan et al., 2007; Wildman, R. E. C. and Miller, B. S., 2004).

\section{Physiological Mechanisms}

There are two forms of diabetes mellitus. Type I, is an insulin-dependent form of diabetes caused by the inability to produce functional insulin (Marieb and Hoehn, 2011; Mirsky et al., 2006). This can be caused by an autoimmune response or genetic dysfunction either at the tissue or hormonal level. Type II diabetes, is generally not insulin dependent because the body can still produce insulin (Marieb and Hoehn, 2011; Mirsky et al., 2006; Gropper et al., 2009). In this case, the body either cannot produce sufficient amounts of insulin, or cannot be functionally utilized either by recognition or receptor dysfunction at the tissue level. Type II diabetes is no longer thought to be the effect of inadequate numbers of receptors but from insufficient glucose transport into tissues. Insufficient production of adiponectin, or excessive production of resistin hormone that causes insulin resistance, can also be responsible for type II diabetes (Beulens et al., 2007; Rostenthal and Glew, 2009; Yokota et al., 2000). Type II generally develops during middle age, but approximately 5\% of all type II diabetics are less than 20 years old and younger people are increasingly diagnosed (CDC, 2011a; Wild, Roglic, Green, Sicree, \& King, 2004; Venkat, Boyle, Thompson, Sorensen, \& Williamson, 2003).

Insulin is produced from beta cells of the pancreas which also produce amylin, a synergistic hormone to insulin, which may help slow the absorption of sugar through the intestines. Insulin is also important for amino acid uptake, protein and lipid synthesis, and 
inhibits energy production pathways such as lipolysis and gluconeogenesis. Adjacent to beta cells are alpha cells which produce glucagon, the antagonist hormone to insulin, responsible for promoting energy production through the release of glucose from tissues back into the blood stream (Marieb and Hoehn, 2011; Rostenthal and Glew, 2009; Miller, et al., 2011; Gropper et al., 2009). Delta cells produce and secrete somatostatin which provides negative feedback to glycogen release from the liver (Gropper et al., 2009). One to two million groups of alpha, beta, and delta cells are named islets of Langerhans and account for $2 \%$ of the pancreatic mass (Marieb and Hoehn, 2011; Mirsky et al., 2006). These hormones work together to balance homeostatic blood sugar levels.

If an insufficient amount of glucose is able to enter target tissues, the body begins to make ketone bodies to use as a fuel source. Ketones are the end product of energy metabolism, and can cause severe damage to the kidneys in high concentrations as it is excreted in the urine, as in ketoacidosis. This rids the body of all its energy and if left untreated can result in the body lapsing into a diabetic coma or shock (Rostenthal and Glew, 2009; Gropper et al., 2009; Mirsky et al., 2006).

\section{Diagnostic criteria}

Fasting blood glucose, FBG, measures the amount of glucose in the blood during a period of fasting and is one of the key tests used to help diagnose type II diabetes (CDC, 2011a). Although the test is most often performed after an overnight fast of at least eight hours, a healthy person may take 2-3 hours for glucose to return to fasting levels postprandial (CDC, 2011a; Mirsky et al., 2006). The American Diabetes Association defines a normal FBG as 70-100 mg/dl, an impaired fasting blood glucose or

pre-diabetes level as a range between $100-125 \mathrm{mg} / \mathrm{dl}$, and a diabetic level as greater than 
or equal to $126 \mathrm{mg} / \mathrm{dl}$ (Table 1). Uncontrolled diabetics may have blood sugar concentrations at $800 \mathrm{mg} / \mathrm{dl}$ or even higher (Mirsky et al., 2006).

Table 1 American Diabetes Association diagnosis criteria of fasting blood glucose for diabetes.

\begin{tabular}{lll}
\hline Normal & Prediabetic & Diabetic \\
\hline $70-100 \mathrm{mg} / \mathrm{dl}$ & $101-125 \mathrm{mg} / \mathrm{dl}$ & $\geq 126 \mathrm{mg} / \mathrm{dl}$ \\
\hline
\end{tabular}

\section{Prevalence and incidence}

Globally, data from year 2000 estimated diabetes prevalence at $2.8 \%$, and that number is expected to double, from 171 million people affected in 2000 to 366 million by 2030 (Wild et al., 2004). Additionally, diabetes is the seventh leading cause of death in the United States (CDC, 2011a). In 2010, diabetes affected 25.8 million Americans, about $8.3 \%$ of the population, and incidence continues to climb (Danaei et al., 2011; CDC, 2011a).

Since 1980, the number of individuals in the US with diabetes has increased more than threefold (CDC, 2011a) (Figures 1 and 2). From 1988-1994 the prevalence of diagnosed diabetes among adults older than 20 years of age averaged 5.1\% in 1988 and 7.7\% by 1994 . This number increased to $12.9 \%$ by $2005-2006(\mathrm{p}=0.0001$ ) (Cowie et al., 2011). 


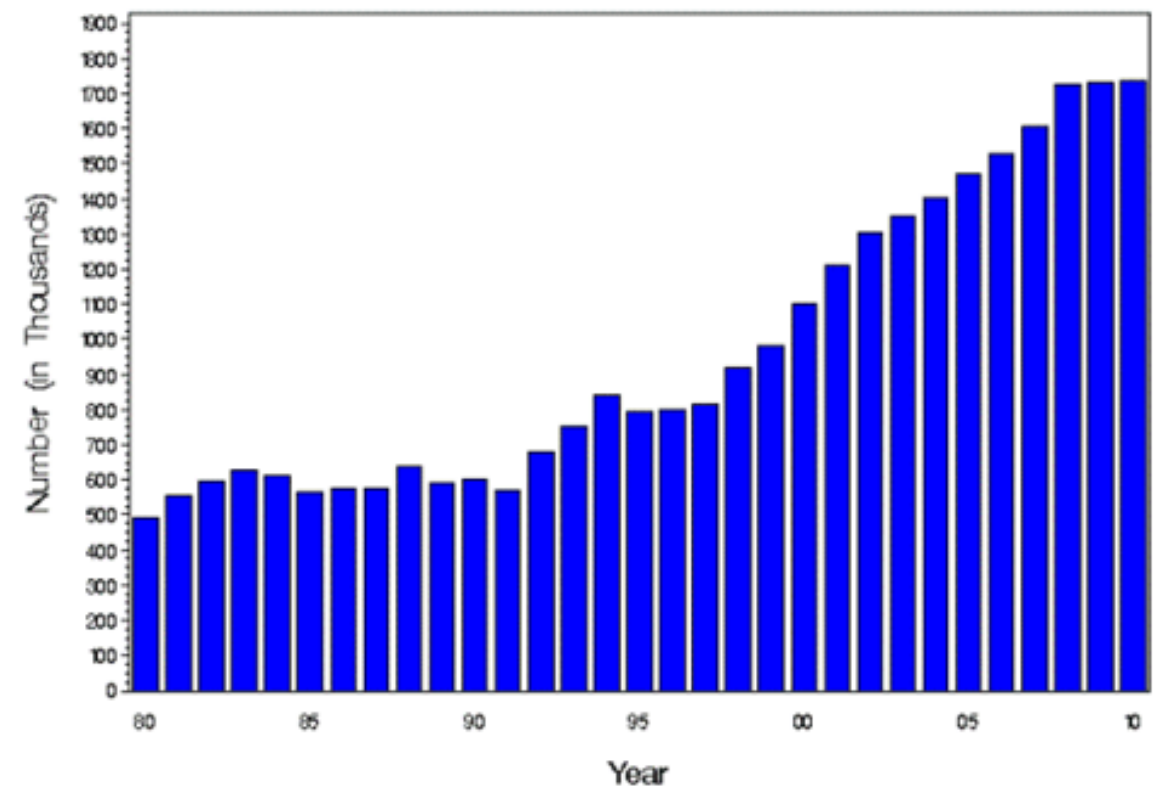

Figure 1 Annual number of new cases of adult (18-79 years) diagnosed with diabetes in the United States 1980-2010 (CDC, 2011a)

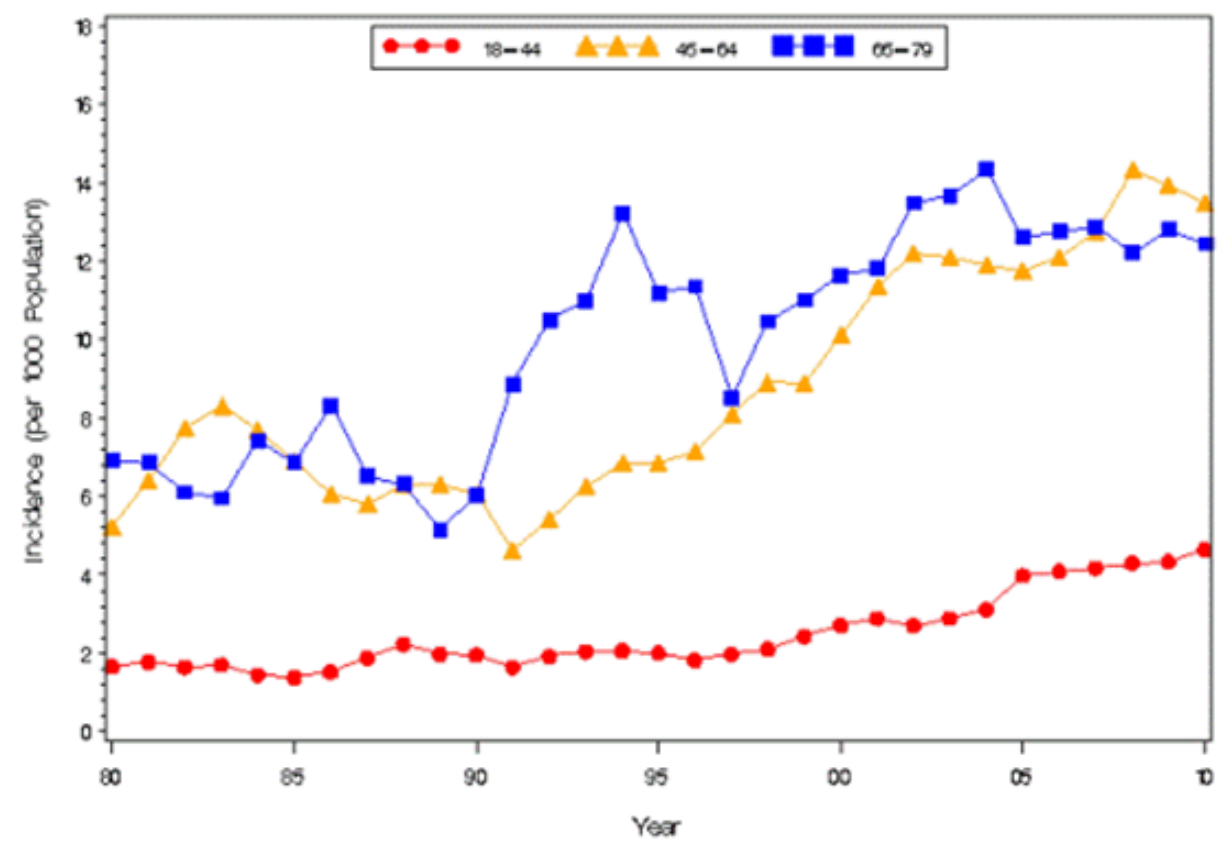

Figure 2. Incidence of diagnosed diabetes by age group per 1,000 population aged 18-79 years, United States, 1980-2010. (CDC, 2011a)

Prevalence of adult diagnosed diabetes in the US in 1990 was $4.9 \%$ and by the year 2000 it had increased 61\%, totaling 7.3\% (Mokdad et al., 2003). By 2001, 
prevalence reached 7.9\%, increasing 8.2\% from the previous year (Figure 3) (Mokdad et al., 2003).

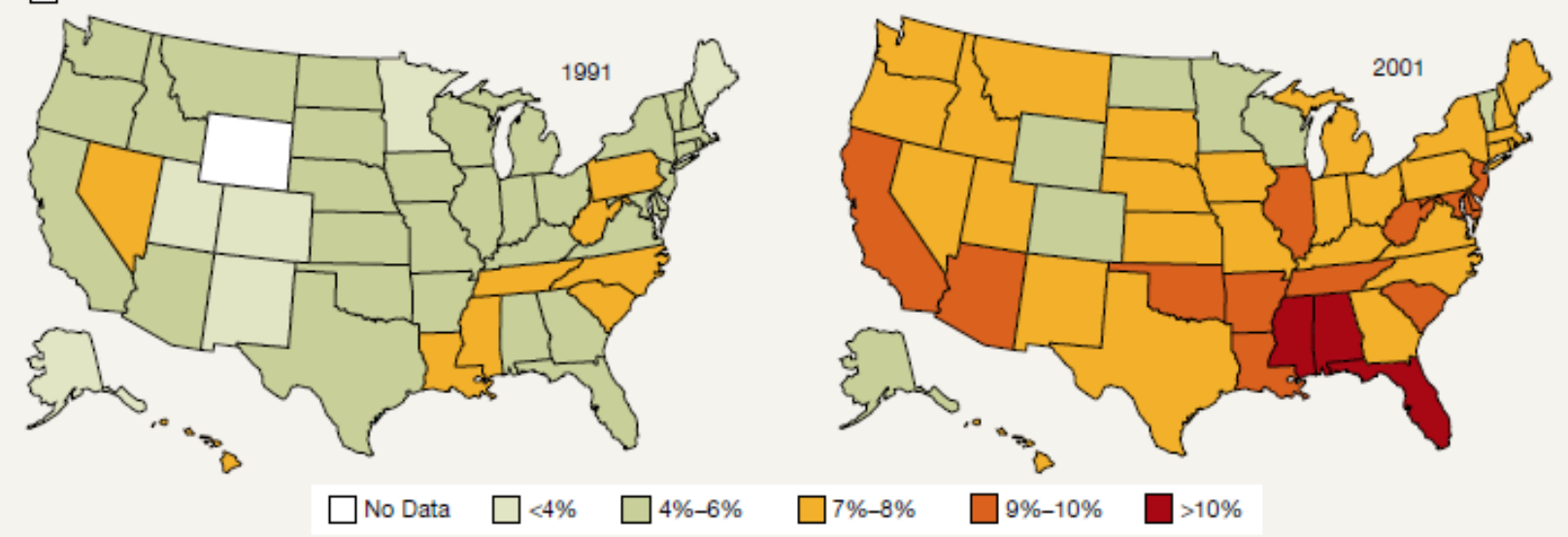

Figure 3. Prevalence of diagnosed diabetes among US adults in 1991 (left) and 2001 (right) (Mokdad et al., 2003).

In 2010, more than 1.9 million people 20 years of age and older in the US were newly diagnosed (CDC, 2011a). . Of these, 1,052,000 were people aged 45-64; 465,000 were between the ages of 20-44; and 390,000 were older than 65 years of age. Additionally, 215,000 people under 20 years of age were newly diagnosed (CDC, 2011a). Increasing prevalence of diabetes is observed across all age groups. It is estimated 8.5 out of 100,000 people between the ages of $10-19$ years or 3,600 youth less than 20 years of age were diagnosed each year between 2002-2005 (CDC, 2011a). . From 20012009, the prevalence of youth with type II diabetes increased by $21 \%$ (Liese et al., 2006).

More than eight of every 100 Americans have diabetes (CDC, 2011a). . If current trends continue one in three Americans born after year 2000 will develop diabetes (Wild et al., 2004; Venkat et al., 2003). In 2007, diabetes was the primary cause of death for 71,382 Americans. Additionally, diabetes was a contributing factor to the deaths of 160,022 more Americans that same year (CDC, 2011a). . 


\section{Demographic risk factors of diabetes}

Diabetes and impaired fasting glucose levels disproportionately affect some populations (Cowie et al., 2006, 2011). Significant trends are observed with age, gender, race/ethnicity, and socioeconomic status. Research often adjusts blood glucose and diabetes data for differences in these variables. In 2010, prevalence of diabetes was higher among men than women, the elderly, people of low socio-economic status, and in non-Hispanic Blacks and Mexican Americans compared to other race/ethnic groups (CDC, 2011a). .

Men are disproportionately affected by diabetes, where $11.8 \%$ of men over 20 years of age are diabetic compared to $10.8 \%$ of women (CDC, 2011a). . Men also have a higher risk of impaired fasting glucose levels than women across all racial/ethnic groups and ages, and have higher prevalence of diabetes (CDC, 2011, Dunstan et al., 2002, Cowie et al., 2006). Dunstan et al., (2002) reported that 8.4\% of males between 25-34 years of age had impaired fasting glucose, whereas only $2.1 \%$ of women of the same age had impaired fasting glucose levels. Similarly, Cowie et al., (2006) observed 37.2\% (95\% CI 32.6-42.1) of US men between 20-39 years old had impaired fasting glucose (5.6-7.0 mmol/l, $100.9-126.13 \mathrm{mg} / \mathrm{dl}$ ) compared to only $22.9 \%$ (95\% CI 19.8-26.3) of women.

The factor that is most associated with diabetes prevalence is age (CDC, 2011a; Liese et al., 2006). Diabetes affects $26.9 \%$ of individuals greater than 65 years of age, approximately 10.9 million people (CDC, 2011a). . Prevalence of diabetes increases with age such that $26.8 \%$ of people over 65 years of age have diabetes whereas $3.7 \%$ of people between the ages of 20-44 have diabetes (CDC, 2011a). . Prevalence of diabetes among 15-19 year olds was 3.35 (95\% CI 3.23-3.47) in 1000 youth (Liese et al., 2006). 
Race/ethnicity has also been associated with diabetes prevalence and fasting blood glucose values. In the Non-Hispanic Black population, $18.7 \%$ or 4.9 million have diabetes compared to $10.2 \%$ or 15.7 million among Non-Hispanic Whites (CDC, 2011a). . Cowie et al., (2006) observed associations between race/ethnicity, concluding that impaired fasting glucose was most prevalent in Mexican Americans between 20-39 years of age ( $\mathrm{p}<0.00001)$, compared to other ethnicities, where $40.1 \%$ (95\% CI 35.4-44.9) of the Mexican American population had a fasting blood glucose between 5.6 to $7.0 \mathrm{mmol} / \mathrm{l}$ , (100.9-126.13 mg/dl). Of this group, $53.5 \%$ (95\% CI 46.7-60.1) were men and 25.7\% (95\% CI 20.3-32.1) were women. Cowie et al., (2006) found that 30.2\% (95\% CI 25.835.1) of non-Hispanic Whites had an impaired fasting blood glucose levels, whereas 21.3\% (95\% CI 15.8-28.2) of non-Hispanic blacks showed an impaired fasting glucose. Significant differences were also found between men and women of the same ethnicity (Cowie et al., 2006).

Income and socio-economic status also strongly correlates with prevalence of impaired fasting blood glucose values and type II diabetes (Connolly, Unwin, Sherriff, Bilous, \& Kelly, 2000; Evans, Newton, Ruta, McDonald, \& Morris, 2000; McKinlay, Link, Piccolo, Meigs, \& Marceau, 2010; Lee et al., 2005). It is estimated that 17-20\% of people with undiagnosed diabetes are of low socio-economic status and prevalence is higher among low income persons (McKinlay et al., 2010; Robbins, Vaccarino, Zhang, \& Kasl, 2001). Robbins (2001) studied men and women between 40-74 years of age and observed income was more strongly associated with diabetes than education or occupational status. Socio-economic status was also shown to be inversely associated with prevalence of diabetes more strongly in women than men. Robbins (2001) measured 
income by the poverty income ratio, PIR, where PIR is calculated as the individual or family income divided by the appropriate federal poverty threshold; therefore a PIR of 1.0 or greater is above the poverty line (US census). Robbins (2001) found that $20 \%$ of African American women were diabetic with a mean PIR of $2.04( \pm 0.05)$ and $13.2 \%$ of White women were diabetic with a higher mean PIR of $3.38( \pm 0.05)$. Socio-economic status was not shown to be significantly associated with diabetes prevalence among men. African American men had a PIR value of $2.3( \pm 0.06)$ with $18.8 \%$ diabetic and $13.9 \%$ of White men had diabetes with a PIR of $3.62( \pm 0.05)$ and $13.9 \%$.

Education level also influences diabetes prevalence. Prevalence of diabetes decreases with increasing education level; and diabetes was observed more than twice as frequently among individuals who did not complete high school (15.6 per 1000 people) compared to those who graduated high school (7 per 1000) (McKinlay et al., 2010).

Genetic physiological, and behavioral risk factors of diabetes

Genetic risk factors

Genetic predisposition can play a critical role as a potential risk factor for diabetes. Though there are probably many unidentified alleles associated with diabetes, an individual with the allele type of gene TCF7L2 on chromosome 10q, is at significantly higher risk of diabetes. Scott et al., (2006) estimated that in an Icelandic population having one copy of this allele increases diabetes risk by $45 \%$ and having two copies increases risk by $141 \%$ (Smart, 2007). Eighty-five percent of type II diabetics have an immediate family member that is also diabetic. A child born to two diabetic parents has a $60 \%$ chance of also developing type II diabetes, this risk with one diabetic parent or sibling increases risk by $3 \%$ after reaching 40 years old and $10 \%$ after age 60 . 


\section{Behavioral risk factors}

Diet and obesity is a major risk factor for diabetes. Obesity is strongly associated with diet, high blood sugar, physical inactivity, and chronic inflammation (Awazawa et al., 2011). Chronic inflammation causes the release of cell signaling molecules such as tumor necrosis factor alpha, TNF- $\alpha$. TNF- $\alpha$ inhibits cell receptors that facilitate glucose out of the blood and into tissues. (Kalupahana, Moustaid-Mousee, \& Claycombe, 2012; Gropper et al., 2011; Marieb and Hoehn, 2011). Obesity can also increase the production of the hormone resistin. Resistin is released from adipose tissue and decreases the body's sensitivity for insulin. Resistin is produced in excess in genetically and diet induced obesity (Beulens et al., 2007).

Since glucose is the energy source for working muscles, physical activity can reduce blood glucose concentration by facilitating glucose uptake from the blood into tissues, through transporters such as GLUT4 which are insulin independent. (Wildman, R. E. C. and Miller, B. S., 2011). Lack of physical activity does not stimulate GLUT4 transporters keeping more glucose in the blood. Physical activity can reduce the necessary amount of insulin needed to maintain blood glucose levels and thus increase the body's sensitivity to insulin (Lee et al., 2005; Wildman, R. E. C. and Miller, B. S., 2011; Gropper et al., 2011).

\section{Impact on quality of life}

In 2007, diabetes was directly responsible for 71,382 deaths in the United States, and contributed to an additional 160,022 deaths, totaling 231,404 deaths that year (CDC, 2011a). Additionally, diabetes is responsible for significant health complications, including being the leading cause of adult blindness, kidney failure, and non-traumatic 
lower limb amputations. In 2008, diabetes was responsible for $44 \%$ of new cases of kidney failure totaling 202,290 diabetic people on chronic dialysis or with kidney transplant. Furthermore, diabetes is the underlying cause of $60 \%$ of non-traumatic lower limb amputations, resulting in 65,700 amputations in 2006 (CDC, 2011a). .

\section{National impact}

Diabetes is also a significant macroeconomic burden. In 2002, estimated costs of diabetes were $\$ 132$ billion, where $\$ 91.8$ billion was due to direct medical costs and $\$ 23.2$ billion was spent on care (43.9\% inpatient hospital care, $15.1 \%$ nursing home care, $10.9 \%$ office visits) and $\$ 17$ billion on indirect costs such as work loss. Complications due to diabetes cost $\$ 24.6$ billion, and an additional $\$ 44.1$ billion was spent on work loss,

disability, and premature mortality excess prevalence of medical conditions (Hogan, Dall, \& Nikolov, 2002). In 2007, diabetes cost the US $\$ 116$ billion directly on medical fees (Zhang et al., 2009; CDC, 2011). An additional cost of $\$ 58$ billion was due to work loss, disability, and morbidity, making the total costs of diabetes that year $\$ 174$ billion (Zhang et al., 2009). This makes the cost of diabetes greater than the combined cost of annual coronary heart disease (108.9 billion) (Heidenreich et al., 2011) and medical costs of cancer (48.1 billion) (CDC, 2011b).

\section{Individual impact}

About $25 \%$ of national health care funds are spent on conditions attributable to diabetes (Hogan et al., 2003). These costs impact individuals and households. In 2002, a healthy individual averaged yearly medical costs of about $\$ 2,560$ (Hogan et al., 2003). Diabetics are estimated to pay 2.3 times more in medical care than non-diabetics of the 
same age, increasing the average annual individual expenditure to $\$ 11,744-13,242$

(CDC, 2011; Hogan et al., 2003).

\section{Alcohol}

\section{Components and mechanism}

Alcohol in its simplest form is ethanol $\mathrm{CH}_{3} \mathrm{CH}_{2} \mathrm{OH}$ and is largely absorbed in the small intestine; and metabolized primarily in the liver and secondarily metabolized in the stomach, kidneys, and lungs (Rosenthal and Glew, 2009). The rate of alcohol absorption can vary between $10 \mathrm{mg} / 100 \mathrm{ml}$ blood/hour to $40 \mathrm{mg} / 100 \mathrm{ml}$ blood/hour and is dependent upon whether food is consumed at the same time and the macronutrients within that food (Smart, 2007). Foods containing fat and protein slow gastric emptying, so consuming alcohol with these foods can slow alcohol absorption (Wildman, R. E. C. and Miller, B. S., 2011; Gropper et al., 2011; Rosenthal and Glew, 2009; Parnell, West, \& Chen, 2006). Ethanol is primarily metabolized by alcohol dehydrogenase, $\mathrm{ADH}$, found in mitochondria and cytosol, and converted into acetaldehyde. ADH is found in high concentration in mitochondria and cytosol of hepatocytes (Rosenthal and Glew, 2009).

$$
\text { Ethanol }+\mathrm{NAD}^{+} \rightarrow \text { acetaldehyde }+\mathrm{NADH}+\mathrm{H}^{+}
$$

Acetaldehyde is then oxidized by $\mathrm{NAD}^{+}$which is dependent on aldehyde dehydrogenase.

$$
\text { Acetaldehyde }+\mathrm{NAD}^{+} \rightarrow \text { acetate }+\mathrm{NADH}+\mathrm{H}^{+}
$$

Acetate is converted to the energy molecule acetyl-CoA by cytoplasmic acetate thiokinase. The acetyl-CoA generated is used for cholesterol and fatty acid synthesis and be used to fuel and eventually oxidized to $\mathrm{CO}_{2}$ and water.

$$
\text { Acetate }+\mathrm{CoASH}+\mathrm{ATP} \rightarrow \text { acetyl-CoA }+\mathrm{AMP}+\mathrm{PPi}
$$

\section{Consumption patterns}


Among adults over the age 18, the National Institute on Alcohol Abuse and Alcoholism survey estimates over $71 \%$ of all adult men and $59.6 \%$ of all adult women had at least one alcoholic drink in their lifetime (SAMHSA, 2012). In 2011, 51.5\% of adults in the US over 18 years of age are considered regular drinkers (having $\geq 12$ drinks per year), over 130 million people; whereas $13.6 \%$ of adults were defined as infrequent drinkers, (having between 1-11 drinks per year). Over $8 \%$ of women and $9.55 \%$ of men report drinking 2-3 times per month. (SAMHSA, 2012; CDC, 2011).

Overall, men are reported to consume larger amounts of alcohol and consume alcohol more frequently than women (CDC, 2011; SAMHSA, 2012; Johnston, O’Malley, Bachman, \& Schulenberg, 2010; Flanagan et al., 2000; White \& Rabiner, 2012). Thirtynine percent of adult women and $28 \%$ of adult men do not report drinking (SAMHSA, 2012). Of this population that does not report drinking, $22 \%$ of all adult women and $11 \%$ of adult men are lifetime abstainers (SAMHSA, 2012).

Binge drinking is also more prevalent among men (SAMHSA, 2012; Johnston et al., 2010). Forty-three percent of men report having five or greater drinks within two hours, while just under a quarter of women or $22 \%$ of women say they had at least four or greater drinks within two hours (SAMHSA, 2012). On days that alcohol is consumed over $42 \%$ of men say they drink three or more drinks where $48 \%$ of women report they only have one drink (SAMHSA, 2012). Alcohol consumption is also most prevalent among White non-Hispanic populations compared to other race/ethnic populations (SAMHSA, 2012; CDC 2011, Robbins et al., 2001). White populations have the largest percentage of regular consumers, at 55\% $( \pm 0.48)$ and the lowest percentage of lifetime abstainers at $17.3 \%( \pm 0.37)$. 
Increased prevalence of alcohol consumption has also been shown to increase with education level and income (Table 2) (CDC, 2011a). . Over 64\% of individuals with a bachelor's degree are regular drinkers where over $34 \%( \pm 0.94)$ of individuals not holding a high school diploma consume alcohol. Additionally, more than $65 \%( \pm 0.65)$ of individuals earning over $\$ 100,000$ annually are considered regular drinkers, where $47.2 \%$ $( \pm 0.96)$ of those making $\$ 35,000-\$ 49,999$ annually are regular drinkers. Those making over $\$ 100,000$ also have the lowest percent of lifetime abstainers $(13.9 \% \pm 0.75)$.

Table 2. Percent (SD) of descriptive socio-demographics prevalence of alcohol consumption (CDC, 2011a).

\begin{tabular}{lll}
\hline & \% Lifetime Abstainer & $\begin{array}{l}\text { \% Current Regular Drinker } \\
\text { (consuming } \geq 12 \text { drinks/ year) }\end{array}$ \\
\hline Age & $20.8(0.48)$ & $56.8(0.57)$ \\
$18-44$ & $15.5(0.46)$ & $51.8(0.66)$ \\
$45-64$ & $21.5(0.86)$ & $41.1(0.98)$ \\
$65-74$ & $31.8(1.01)$ & $29.9(1.02)$ \\
$75+$ & & \\
Race/ Ethnicity & $30.2(0.81)$ & $42.1(0.84)$ \\
Hispanic/ Latino & $43.7(1.36)$ & $34.1(1.22)$ \\
Asian & $17.3(0.37)$ & $54.9(0.48)$ \\
White & $29.5(0.85)$ & $39.3(0.86)$ \\
Black & & $34.9(0.94)$ \\
Education & $29.2(0.87)$ & $46.6(0.74)$ \\
Less than HS diploma & $18.8(0.57)$ & $64.1(0.65)$ \\
HS diploma & $14.2(0.48)$ & \\
Bachelor's Degree + & & $47.2(.96)$ \\
Income & $20.2(.79)$ & $54.2(.85)$ \\
\$35,000-\$49,999 & $17.7(.69)$ & $58.1(1.09)$ \\
\$50,000-\$74,999 & $14.9(.84)$ & $65.8(.89)$ \\
\$75,000-\$99,999 & $13.9(.75)$ & \\
\$100,000+ &
\end{tabular}

\section{Definitions of alcohol measurements}

Though there are variable definitions of an alcoholic "drink", the National Institute of Alcohol Abuse and Alcoholism (NIAAA) defines one drink of alcohol as equal to 0.6 fluid ounces (oz) alcohol or $14 \mathrm{~g}$ pure alcohol. Commonly, a single drink is 
defined as $12 \mathrm{oz}$ beer, $8-9 \mathrm{fl} \mathrm{oz}$ malt liquor, $5 \mathrm{oz}$ wine, or $1.5 \mathrm{oz}$ of an 80 proof spirit (Dasgupta, 2012; SAMHSA, 2012).

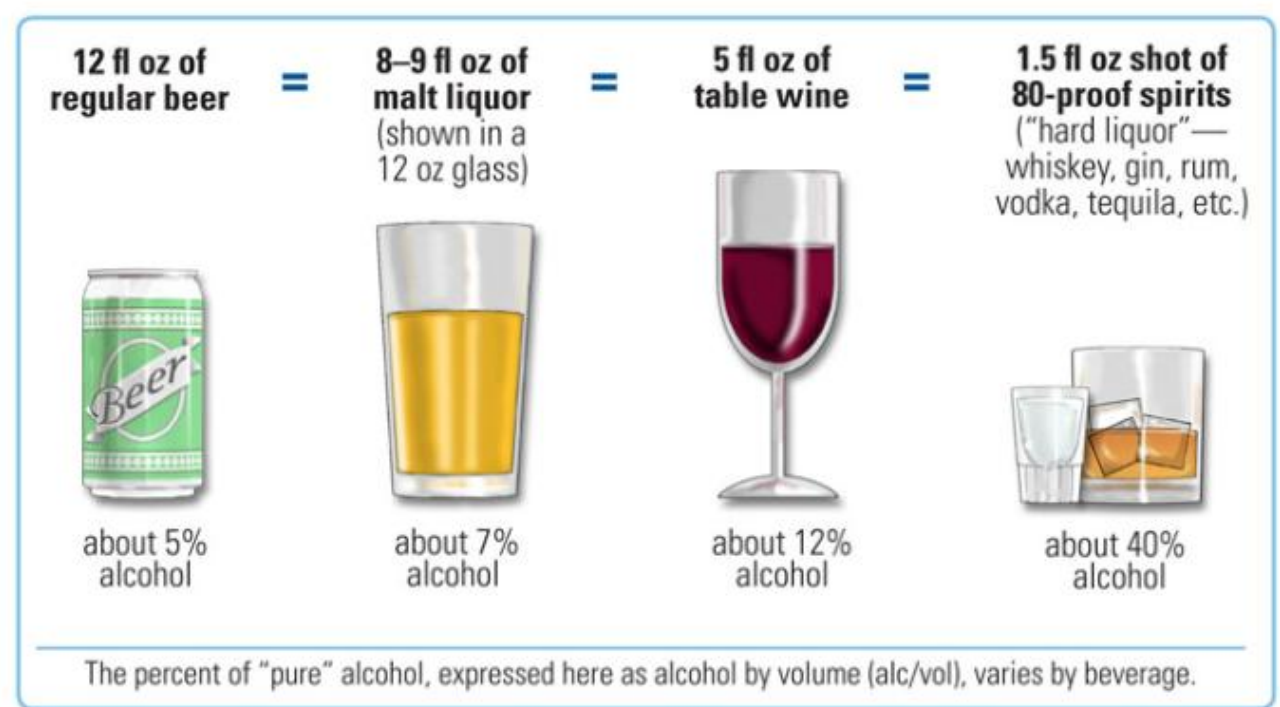

Figure 4. NIAAA standards for one alcoholic drink (SAMHSA, 2012).

\section{Alcohol consumption and binge drinking}

The NIAAA defines moderate alcohol consumption as no more than four drinks on any single day and no more than 14 drinks per week for men and no more than three drinks on any single day and seven drinks per week for women. Drinking above these guidelines is considered heavy drinking. Binge drinking is determined by the NIAAA as having greater than five drinks within two hours for men and having greater than four drinks within two hours for women.

Abel, Kruger, \& Friedl (1998) administered a survey to Michigan physicians defining light, moderate, heavy, and abusive drinking. The results of this study (Table 3) found the average definitions of light drinking was consuming 1.2 drinks per day, 4.3 drinks per week, or 15.7 drinks per month. A moderate drinker was defined as an individual who would consume 2.2 drinks per day, 10.0 drinks per week or 39 drinks per 
month and a heavy drinker was defined as consuming 3.5 drinks per day, 18.9 drinks per week, and 67.4 drinks per month. More than 3.5 drinks per day, 27.8 drinks per week, or 100 drinks per month were termed abusive by the physicians that were surveyed (Abel et al., 1998).

This study demonstrated general definitions of light, moderate, and heavy drinking which was relative to current NIAAA guidelines, however, some ambiguity remains among the general population (Abel et al., 1998). Alcohol consumption is usually measured by self-reported data, and what is considered light, moderate, and heavy drinking may vary between drinkers as well as researchers, and can be influenced by age and gender of the drinker.

Table 3. Definitions of light, moderate, and heavy drinking habits from results (Abel et al., 1998)

\begin{tabular}{lllll}
\hline & Light & Moderate & Heavy & Abusive \\
\hline \multirow{2}{*}{ Daily } & $\leq 1.2$ & 2.2 & 3.5 & $>3.5$ \\
Weekly & $\leq 4.3$ & 10 & 18.9 & $\leq 27.8$ \\
Monthly & $\leq 15.7$ & 39 & 67.4 & $\geq 100$ \\
\hline
\end{tabular}

\section{Epidemiology of consumption among young adults}

Since 1980, alcohol has been the most used substance among young adults (Johnston et al., 2010). Forty percent of college students and approximately $30 \%$ of high school seniors report binge drinking. More than $61 \%$ of $18-25$ year olds and almost $55 \%$ of people over age 26 in the US have reported using alcohol in past month (SAMHSA, 2012). In California, $59 \%$ of $18-25$ year olds and $53 \%$ of people 26 or older have reported alcohol use in the past month (SAMHSA, 2012). 
Prevalence of alcohol consumption increases around age 18 to age 22 before declining and leveling off by age 25 (Johnston et al., 2010). This pattern is observed among college students as well as young adults not in college. It was also observed that consistently from 1980 through 2010 young adult males report consuming 15-20\% more alcohol than their female peers regardless of college enrollment status (Johnston et al., 2010).

Johnston et al., (2010) examined whether college enrollment played a role on alcohol consumption among young adults. They conducted several cross sectional studies over 30 years to assess the drinking patterns of 19-22 year olds, comparing those enrolled in college and those not enrolled. Alcohol consumption was determined by survey in reference to the past 30 days. Data showed that from 1980-2010; college students consistently reported drinking approximately $5 \%$ more than young adults of the same age not in college (Figure 5). In 1980, 81\% of college students consumed alcohol. By 2009 rates declined to $64 \%$. Of the young adults not in college, $76 \%$ reported consuming alcohol in 1980 which declined to $58 \%$ by 2009 . 


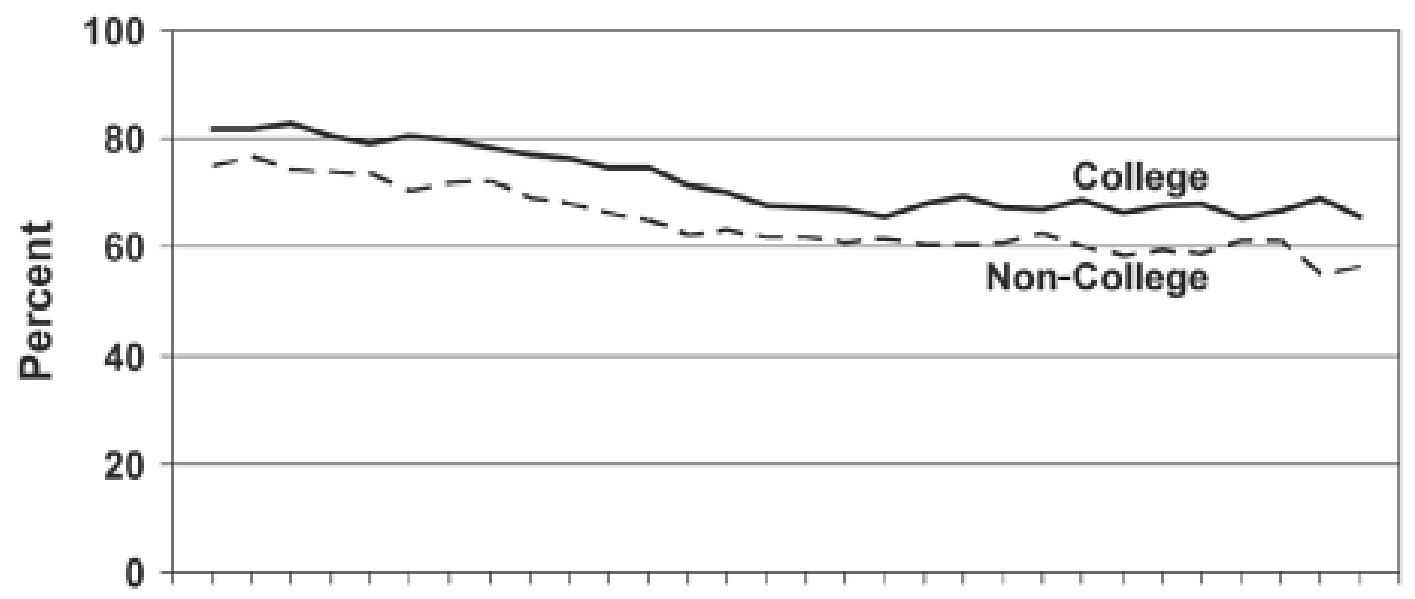

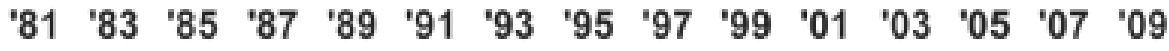

\section{Year of Administration}

Figure 5. Prevalence of alcohol use from 30 day surveys of college students and noncollege young adults aged 19-22 from 1980-2009 (White and Rabiner, 2012).

Binge drinking is also more prevalent among college students than non-college young adults (Johnston et al., 2010). Approximately 40\% of college students report binge drinking, or having more than five drinks in one sitting (Johnston et al., 2010). Since 1980, college students consistently reported having a 5\% higher prevalence of binge drinking than young adults of the same age (Figure 5). However, prevalence of binge drinking overall declined in both groups. In 1980, $42 \%$ of college students reported binge drinking and by 2009, only 37\% report binge drinking (Figure 6). Non-college young adults showed a stronger decline since 1980, with prevalence decreasing from $40 \%$ to $30 \%$ by 2009 . Behaviors of drinking patterns have been shown to change from age 18 to mid-twenties (Johnston et al., 2010). 


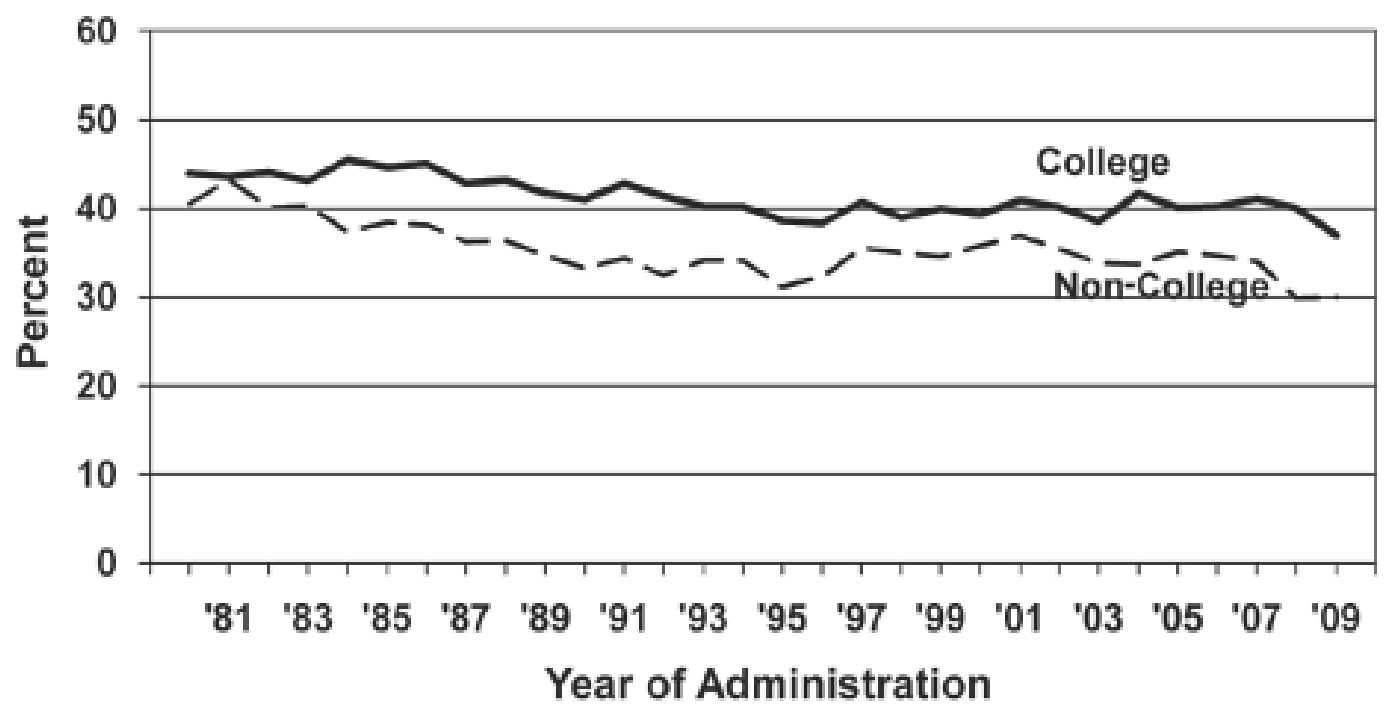

Figure 6. Prevalence of binge drinking from past two week surveys of college students and non- college young adults aged 19-22 from 1980-2009 (White and Rabiner, 2012).

A second study by Johnston et al., 2010, examined binge drinking among college and non-college students between the ages of 19-25 years. Beginning senior year of high school, students who were not college bound reported higher frequency of binge drinking, averaging 1.95 nights in the past two weeks for males and 1.55 nights for females. Male college bound high school seniors reported drinking 1.75 nights in the past two weeks and 1.4 nights for females. The cohort study continued to examine drinking habits and by the start of college enrollment, at a modal age of 19 years, college students matched the frequency of binge drinking to young adults of the same age. By 21 years of age, the rate of binge drinking among college students rapidly increased, passing frequency of non-college young adults, peaking at a frequency of 2.25 times in the past two weeks in males and 1.7 times for females. Frequency of binge drinking declines after age 21 among both males and females in college and reaches the frequency of noncollege young adults by age 25 . Non-college peers exhibited a nearly static frequency of binge drinking between the ages of $18-25$, with a slight increase at age 21 in males. This 
suggests that the college lifestyle or environment may influence alcohol use and consumption behaviors.

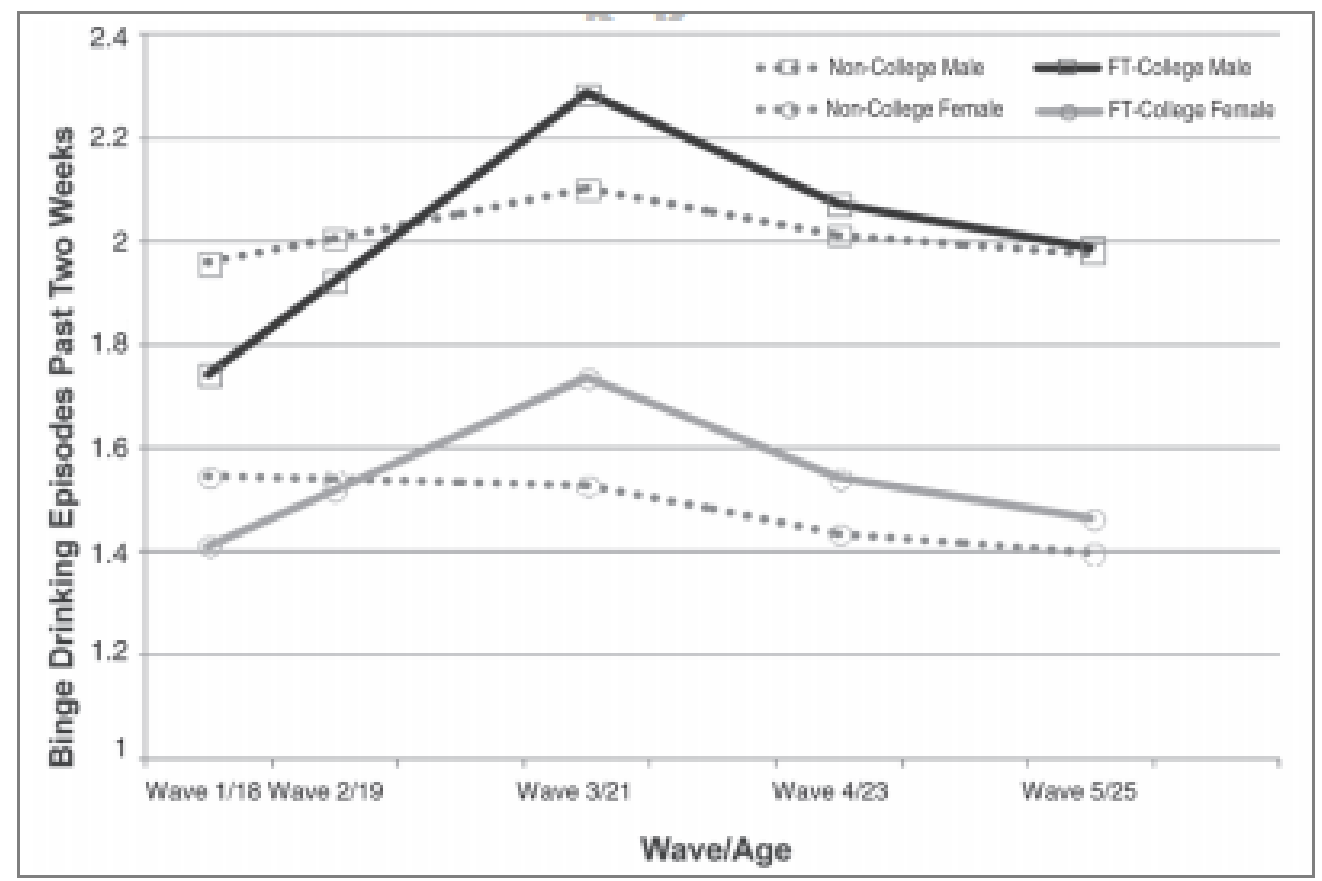

Figure 7. Prevalence of binge drinking episodes from past two week surveys of college students and non-college young adults by sex beginning 4th year of high school through first three years of college. (White and Rabiner, 2012)

\section{Health and physiological effects of alcohol}

Negative consequences

Immediate effects of alcohol consumption can reduce inhibitions, disrupt coordination, cause confusion, concentration problems, and in excess, lead to coma and death. These effects can then increase the risk of car accidents and engagement of risky or violent behavior which can result to suicide and homicide (SAMHSA, 2012). In the US there were 25,692 alcohol induced deaths not including car accidents and homicides 
in 2011 (SAMHSA, 2012). Risks of chronic consumption can cause alcohol dependence, health and physiological problems, and cancer (SAMHSA, 2012).

Physiological risks associated with chronic or abusive alcohol consumption are liver disease, some cancers, and brain, reproductive, and endocrine damage. It is estimated $75 \%$ of esophageal cancers and $50 \%$ of mouth, pharynx, and larynx cancers are associated with alcohol abuse, about 2-4\% of all cancers (Dasgupta, 2012).

Dementia may be caused by the impact of abusive alcohol consumption by decreasing the size of the pre-frontal cortex, impacting judgment and decreasing memory (Dasgupta, 2012). Chronic alcohol consumption can also damage the endocrine system, including direct impacts on the reproductive system. In females, alcohol abuse can disrupt the normal menstrual cycle and prevent or delay ovulation. It can also cause demineralization of bones by inhibiting ossification hormones (Dasgupta, 2012).

Liver disease from alcohol is responsible for 15,990 deaths per year (SAMHSA, 2012). Alcohol induced liver disease is often diagnosed in three main stages, fatty liver, hepatitis, and cirrhosis (Smart, 2007). Alcohol travels through the blood and impacts organs with a larger blood supply more significantly than organs with less blood perfusion. Seventy five percent of all blood from the gastro-intestinal tract goes directly to the liver making it highly sensitive to alcohol (Marieb and Hoehn, 2011; Gropper, Groff, \& Smith, 2011).

Fatty liver is the primary stage of liver disease and can develop as soon as a few days of heavy drinking. Ninety percent of alcoholics develop a fatty liver but this can also be reversed by the liver's ability of regeneration. After a period of abstinence the liver can self heal, however, if an extensive period of heavy drinking has occurred, fatty liver 
can cause further damage (Smart, 2007). If heavy drinking continues after fatty liver development, $10-35 \%$ will continue to develop into alcoholic hepatitis and 10-20\% will develop liver cirrhosis (Dasgupta, 2012).

The more severe stages of liver disease include alcoholic hepatitis, inflammation of the liver which is caused by further damage from fat accumulation. Inflammation from excess fat prevents the liver from filtering toxins, which can increase the risk of death from hepatitis. (Smart, 2007; Dasgupta, 2012) Cirrhosis can develop either from chronic inflammation or accumulation of toxins, which kills liver cells and become replaced by scar tissue. Development of scar tissue inhibits normal blood circulation which can disrupt blood pressure and cause damage to organs (Smart, 2007). Though fatty liver can be reversed; once the liver cells have died, damage is irreversible even if alcohol consumption has stopped (Smart, 2007). Some symptoms associated with liver damage are weakness, fatigue, weight loss, nausea, vomiting, diarrhea, abdominal pain, and jaundice (Dasgupta, 2012). Overall, chronic and excessive alcohol consumption has major health risks and complications as well as facilitates behavioral changes.

\section{Health benefits}

Though excessive alcohol consumption can cause a number of harmful sideeffects, many studies have shown moderate consumption of alcohol to be associated with health benefits. Some of the described benefits include decreased risk of coronary heart disease, stroke, cardiovascular disease, arthritis, age-related dementia, some cancers, diabetes, the common cold and it has been observed to increase longevity (Wildman, R. E. C. and Miller, B. S., M. 2011; Watkins, 1997; Smart, 2007). 
Moderate consumption of alcohol can help prevent against free radical damage by providing antioxidants which reduce damage caused by free radicals (Maxwell et al., 1994; Watkins, 1997). A free radical is an atom or molecule that has an unpaired electron in its valence shell. Free radicals are ubiquitous throughout the body and can cause damage by breaking lipid membranes, releasing proteins and organelles, and can kill cells. Antioxidants are molecules like polyphenolic flavonoids found in alcoholic beverages, tea, and vegetables that can give up electrons to the radical molecule neutralizing its ability to cause damage (Watkins, 1997).

Wines specifically have been observed to contain high concentrations of antioxidants in the body. Maxwell, Cruickshank, \& Thorpe (1994), observed drinking 5.7 $\mathrm{ml}$ red wine with dinner increased antioxidant concentration in the blood by $14 \%$ over basal values (Maxwell et al., 1994; Watkins, 1997). Fasting blood samples were collected from five male and five female students to provide basal serum antioxidant activity. Each student then ate a meal within 30 minutes and blood tests were administered at regular intervals for the following four hours. The same students then repeated the experiment, but included a glass of $5.7 \mathrm{ml}$ red wine with the meal. Peak antioxidant concentration occurred after 90 minutes of consumption, and antioxidant concentrations remained significantly high $(\mathrm{p}<0.001)$ for four hours after consuming wine with a meal.

Cardiovascular disease is a major cause of death in the US, responsible for about $25 \%$ of all deaths (Wildman, R. E. C. and Miller, B. S. et al., 2011). The buildup of low density lipoproteins, commonly known as 'bad' cholesterol, can deposit along coronary arteries and collect blood platelets, constricting adequate blood flow (Wildman, R. E. C. and Miller, B. S. et al., 2011; Gropper et al., 2011; Smart, 2007; Renaud and Delorgeril, 
1992). Narrowing of coronary arteries can inhibit circulation and cause heart attack, stroke, or heart failure. Alcohol is a vasodilator which can increase vessel diameter allowing more blood to pass even in vessels that are constricted by plaque buildup (Smart, 2007). Evidence that alcohol may inhibit platelet formation had been observed by Renaud and Delorgeril (1992). This study found men in France who consumed 30-50 grams of alcohol per day (about 3-4 drinks/day) decreased the risk for coronary heart disease by $40 \%$ (95\% CI 0.35-0.79).

Moderate alcohol consumption was also observed to decrease coronary heart disease (CHD) in men over 65 by reduced artery plaque buildup (Bofetta and Garfinkel, 1990). Lowest relative risk for CHD was among men who consumed alcohol 1-2 drinks per day. Table 4 demonstrates relative risk of $\mathrm{CHD}$ and number of drinks consumed. Moderate alcohol consumption was found to decrease risk of CHD when compared to those who did not consume.

Table 4. Case control analysis of alcohol consumption and relative risk of coronary heart disease. (Boffetta and Garfinkel, 1990)

Relative Risk of CHD $\quad 95 \%$ CI

\begin{tabular}{lll}
\hline Nondrinker & 1.00 & \\
Occasional drinker & 0.87 & $0.80-0.94$ \\
1 drink/day & 0.80 & $0.75-0.85$ \\
2 drinks/day & 0.80 & $0.75-0.86$ \\
3 drinks/day & 0.87 & $0.79-0.96$ \\
4 drinks/day & 0.78 & $0.70-0.89$ \\
5 drinks/day & 0.83 & $0.70-0.98$ \\
6+ drinks/day & 0.97 & $0.89-1.12$ \\
Irregular drinker & 0.96 & $0.90-1.04$ \\
\hline
\end{tabular}

People with diabetes are at higher risk for cardiovascular disease and some studies show diabetics who consume alcohol may have reduced risk for cardiovascular disease. Ajani et al., (2000) found that men consuming moderate amounts of alcohol had a 
decreased risk of developing coronary heart disease. Relative risk was reduced by $33 \%$ in healthy men and relative risk decreased by $58 \%$ in diabetic men. Healthy men consuming alcohol on a daily or weekly basis exhibited a relative risk of coronary heart disease of 0.61 (95\% CI 0.49-0.78) and 0.82 (95\% CI 0.66-1.02) compared to non-drinkers $(\mathrm{p}<0.0001)$. Relative risk of coronary heart disease in diabetic men consuming alcohol on a daily and weekly basis was 0.42 (95\% CI 0.23-0.77) and 0.67 (95\% 0.42-1.07) $(\mathrm{p}=0.0019)$.

\section{Alcohol and fasting blood glucose and diabetes mellitus}

\section{Mechanisms}

Several studies have suggested that alcohol consumption may increase insulin sensitivity and therefore reduce the risk of type II diabetes. Alcohol is observed to increase adiponectin, a plasma protein derived from adipocytes (Sierksma et al., 2004; Beulens et al., 2007; Joosten et al., 2008; Yokota et al., 2000). The mechanism of how adiponectin can increase insulin sensitivity is poorly understood and its direct receptor remains unknown, but research has shown adiponectin decreases tumor necrosis factor, TNF- $\alpha$, activity and increases insulin receptor substrate, IRS-2, expression in the liver (Sierksma et al., 2004; Awazawa et al., 2011). TNF- $\alpha$ is an inflammatory cytokine and inhibitor of IRS-2 which regulates glucose facilitation into tissues. IRS-2 activation by phosphorylation causes a reaction cascade that transports glucose out of the blood, promoting glycogen synthesis, lipogenesis, protein synthesis, and inhibits gluconeogensis, which transports glucose back into the blood (Gropper et al., 2011; Kalupahana et al., 2012). 


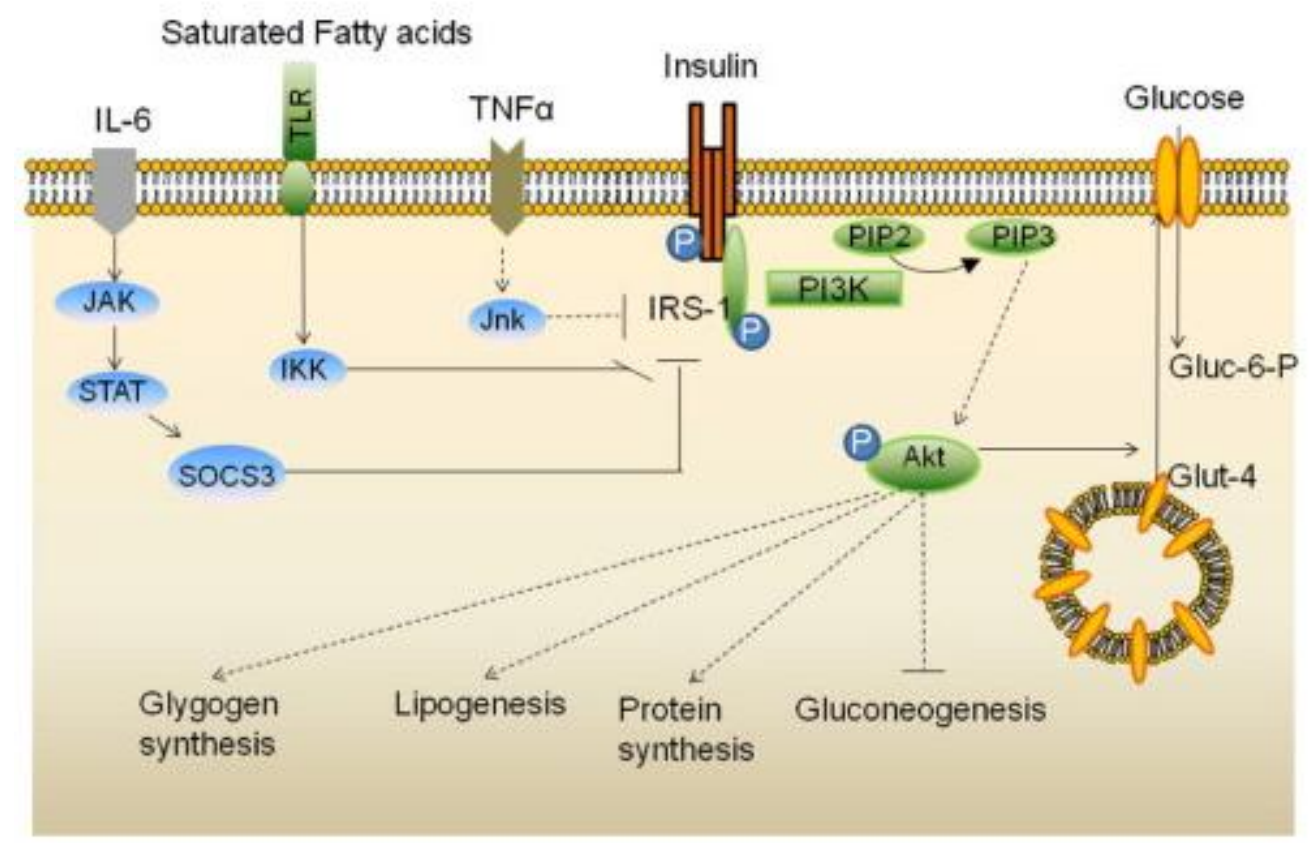

Figure 8. Reaction cascades of inflammatory cytokines and insulin on glycogen synthesis. (Kalupahana et al., 2012).

In skeletal muscle, IRS-2 can stimulate additional glucose transporters like GLUT4 that line the endothelium enhancing glucose facilitation out of the blood. This keeps blood glucose levels from being abnormally high, and decreases the amount of insulin required to facilitate uptake (Gropper et al., 2012). Therefore increasing activity of IRS-2 increases glucose transport out of the blood (Gropper et al., 2012; Kalupahana et al., 2012).

\section{Existing literature and rationale}

Facchini et al., (1994) examined alcohol consumption and insulin sensitivity and plasma glucose concentrations among 40 adults, 22 women and 18 men, by oral glucose tolerance test. Eleven women and nine men reported being light to moderate drinkers, consuming 10-30 g alcohol/day or 0.7-2.1 drinks per day, whereas the other half reported being non-drinkers. This study found plasma glucose was significantly lower among the 
light to moderate drinkers $120.7 \mathrm{mg} / \mathrm{dl} \pm 14.4$ compared to non-drinkers $192.8 \mathrm{mg} / \mathrm{dl} \pm 21.6$, $(\mathrm{p}<0.01)$

Wannamethee, Camargo, Manson, Willett, \& Rimm, (2003) surveyed alcohol consumption of 72,054 women between 25-42 years of age without history of diabetes, heart disease, stroke, or cancer. Results were adjusted for cholesterol levels, body weight, smoking, and contraceptive use. After a 10 year follow up of new diagnoses, a trend for diabetes prevalence was most abundant among ex-drinkers followed by abstainers, with no significant difference found between these groups. Risk for developing type II diabetes was lowest, 0.52 (95\% CI 0.24-1.11), among women who consumed 15-29.9 grams of alcohol or approximately 1-2 drinks per day. Women consuming 0.1-4.9 grams of alcohol per day had a relative risk of 0.74 (95\% CI 0.59-0.93), and women consuming 5-14.9 had risk of 0.58 (95\% CI 0.40-0.84). Though there were few women $(n=837)$ who reported, consuming more than 30.0 grams per day, whose relative risk was 0.64 (95\% CI 0.26-1.57). No significant differences were found between heavy drinkers and light to moderate drinkers.

This same study also analyzed frequency of drinks consumed (Wannamethee et al., 2003). Drinkers were split into two groups, those consuming alcohol 1-3 days/week and those consuming 4-7 days/week. A trend was seen among those drinking 1-3 days/week showed a lower risk 0.29 (95\% CI 0.09-0.91) of developing diabetes than women who consumed alcohol 4-7 days/week 0.62 (95\% CI 0.23-1.68).

Association between body mass index, BMI, and alcohol consumption was also calculated and non-drinkers and abstainers were found to have significantly higher BMI $(\mathrm{P}<0.001)$ compared to those who consumed alcohol. Overall, Wannamethee et al., 
(2003) found light and moderate drinkers exhibited the least risk of developing diabetes, had the least prevalence of a BMI greater than $30 \mathrm{~kg} / \mathrm{m}^{2}$, and the lowest prevalence of high cholesterol and high blood pressure according to individual physician diagnosis when compared to non-drinkers.

Koppes, Dekker, Hendriks, Bouter, \& Heine, (2005) performed a meta-analysis of 15 studies and concluded those consuming 6-48 $\mathrm{g}$ of alcohol (0.4-3.4 drinks) per day had lower relative risk for type II diabetes by an average of 30\%. Of this group, those consuming 12-24 g/day (0.86-1.74 drinks / day) showed the most significant decrease in risk by 0.69 (95\% CI 0.58-0.81). Analysis of these studies found those consuming $\leq 6$ g/day had a relative risk of 0.87 (95\% CI 0.79-0.95), 6-12 g/day 0.70 (95\% CI 0.61-0.79), and 24-48 g/day 0.72 (95\% CI 0.62-0.84) when compared to the non-drinking population. Consumption of $\geq 48 \mathrm{~g} /$ day had a relative risk of type II diabetes similar to those not consuming alcohol, 1.04 (95\% CI 0.84-1.29).

Relative risk of type II diabetes was also observed by analyzing 20 cohort studies. The youngest age at the start of the cohort was 25 years old (Baliunas et al., 2009). Assessing 477,200 individuals, Baliunas et al., (2009) found a U-shaped curve between alcohol consumption and risk of type II diabetes, where individuals who did not consume alcohol had a similar risk as heavy consumers. Men consuming $22 \mathrm{~g} /$ day (1.6 drinks) and women consuming $24 \mathrm{~g} /$ day ( 1.7 drinks) had the lowest risk for developing type II diabetes. Men showed a decreased risk of 0.87 (95\% CI 0.76-1.00) and women showed a decreased risk of 0.60 (95\% CI 0.52-0.69). However, relative risk was observed to increase among men who consumed greater than $60 \mathrm{~g} /$ day ( 4.3 drinks), 1.01 (95\% CI 
0.71-1.44) and women had increased risk when consuming greater than $50 \mathrm{~g} /$ day (3.6 drinks), 1.02 (95\% CI 0.83-1.26).

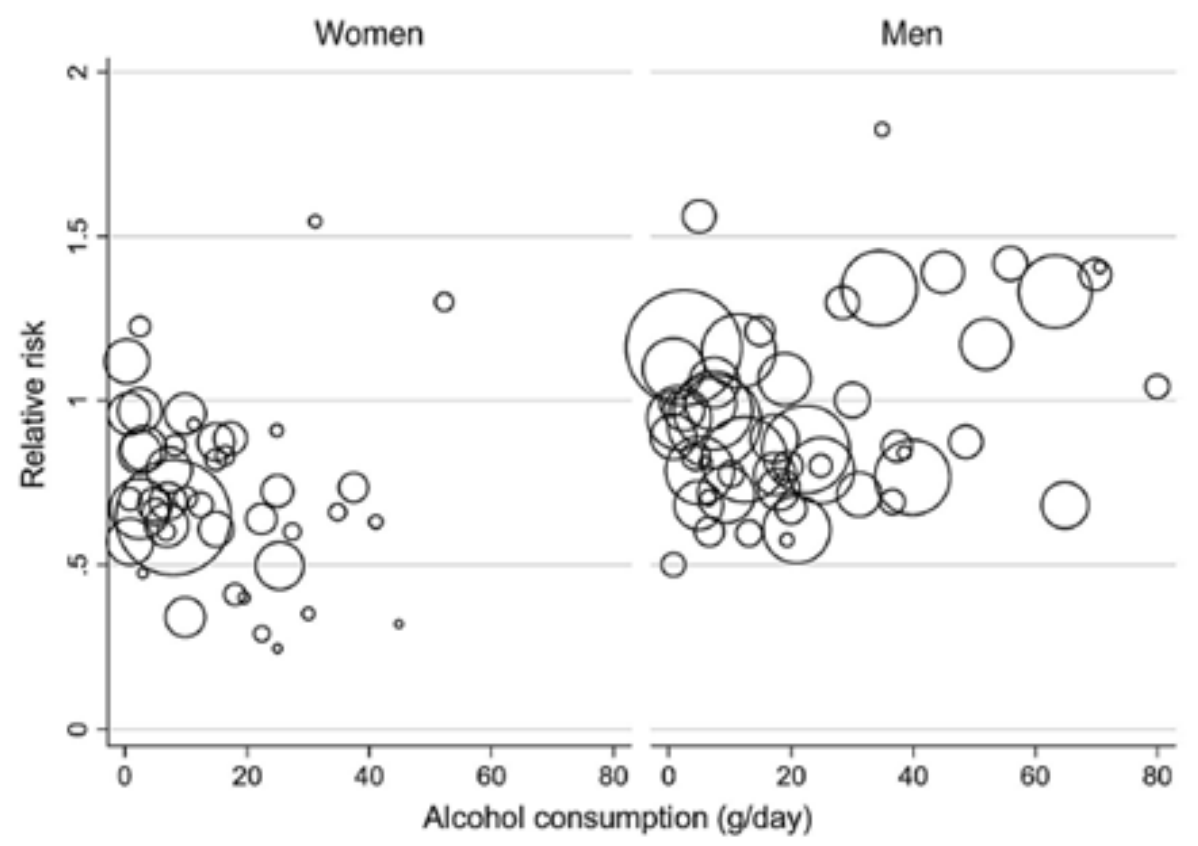

Figure 9. Meta-analysis of twenty studies examining relative risk of diabetes and alcohol consumption in grams per day (Baliunas et al., 2009).

Davies et al., (2002) conducted a randomized controlled diet study with postmenopausal women and alcohol consumption. Fifty-one women were randomly assigned to consume 0,15 , or 30 grams of alcohol per day (or $0,1,2$ drinks) for eight weeks during which insulin concentration and glucose uptake was measured. Significant differences were found in insulin concentration and the rate of glucose uptake across all three levels of alcohol intake. Insulin concentration was highest among the group who did not consume alcohol; the same group exhibited the slowest decline in plasma glucose concentration. Insulin concentration decreased with increasing alcohol consumption with those consuming $30 \mathrm{~g} /$ day group having significantly lower insulin concentration $(p=0.001)$. Rate of glucose disposal was also significantly different among each group, with the women who consumed $30 \mathrm{~g} /$ day showing the highest rate of glucose uptake 
followed by the $15 \mathrm{~g}$ /day group ( $\mathrm{p}<0.001)$. Overall, women who consumed $30 \mathrm{~g}$ of alcohol reduced plasma insulin concentration by $19.2 \%(\mathrm{p}=0.004)$ and insulin sensitivity increased by $7.2 \%,(\mathrm{p}=0.002)$, compared to women who did not consume any alcohol. However, no significant changes were observed in blood glucose concentration.

Researchers in Australia compared insulin sensitivity and alcohol consumption among 154 college students, 81 males and 73 females (Flanagan et al., 2000). This study additionally controlled for diet where each participant was requested to consume at least $200 \mathrm{~g}$ of carbohydrates a day for 3 days, before their FBG test. The participants completed a survey which asked 'How often do you usually drink alcohol' and 'On a day when you drink alcohol, how many drinks do you usually have per week. Their answers regarding alcohol consumption were categorized as: Group 1 consumed no alcohol, Group 2 consumed less than 8 units per week, where 1 unit equals about 8 grams of ethanol, Group 3 consumed 8-12 units, Group 4 consumed 12-20 units per week, and Group 5 consumed more than 20 units per week. After the overnight fast, through intravenous administration, each participant received $0.5 \mathrm{~g}$ of glucose per kilogram body weight over a 3 minute period. Blood sampling was collected through the other arm at $-30,-5,3,5,7$, $10,15,30,45,60,75,90,120$, and 180 minutes after glucose uptake. The mean of two previous collections of fasting blood samples were taken to serve a basal insulin and basal glucose value for each participant. The results showed women exhibited significantly lower FBG, $95.7 \mathrm{mg} / \mathrm{dl}( \pm 5.7)$ than men, $101.08 \mathrm{mg} / \mathrm{dl}( \pm 5.8)(\mathrm{p}<0.0001)$, but women had higher blood insulin concentrations.. A relationship was found between increased insulin sensitivity and increasing alcohol consumption in both men and women $(\mathrm{p}<0.015)$. 
Overall, the literature has found a U-shaped curve where moderate alcohol consumption is associated with decreased risk of type II diabetes, cardiovascular disease, and coronary heart disease when compared to non-drinkers and individuals consuming excess alcohol. Furthermore, moderate alcohol consumption is associated with health benefits such as lower blood glucose concentration, increased insulin sensitivity, and increased concentration of antioxidants in the blood.

\section{Conclusion}

Diabetes is becoming more prevalent and is responsible for a heavy economic burden, morbidity and premature mortality. There is evidence suggesting an association between alcohol consumption and plasma glucose and/or insulin concentration and secretion. This relationship may help develop a better understanding of the risk factors associated with type II diabetes. However, few studies have analyzed the effects of alcohol among a young adult, college population. The objective of this study was to examine the association between alcohol consumption and fasting blood glucose in young adults. Studying these risk factors at an earlier age can help implement behavioral changes delaying the onset of morbidity. Understanding associated risk factors can be used to increase public health efforts towards preventive measures and help stop the growth of the increasing prevalence of diabetes. 


\section{CHAPTER 2}

\section{Methods and Materials}

\section{FLASH study design}

Following the Longitudinal Aspects of Student Health (FLASH) is a prospective cohort study on the California Polytechnic State University, San Luis Obispo, campus examining health perceptions and behavior over several years of a students' college experience. Baseline research began in September 2009 and continued through December 2009. All new full-time freshman students were invited to participate. The FLASH study encompassed an online survey, a physical assessment, as well as three sub-studies; one of resting energy expenditure, one of sun exposure and vitamin D status, and one that examined components of fasting blood for common cardiovascular risk indicators (glucose, triglycerides, total cholesterol, high density lipoproteins (HDL), and low density lipoproteins (LDL) cholesterol). The survey was administered each academic quarter the study occurred by the Social Science Research Center of the California State University Fullerton, whereas data collection of the sub-studies varied throughout, as indicated in Table 4. Following the baseline Fall 2009 study, four follow-up surveys were conducted. The first follow-up was held during the spring academic quarter 2010 (MarchJune). The second follow-up occurred fall quarter 2010 (September- December) and added a second incoming cohort of first year freshman students. Follow-up studies were also conducted Spring 2011 and Spring 2012 (March- June) for both cohorts. Blood tests were conducted during Fall 2010, Spring 2011, and Spring 2012. In Fall 2010, 204 selfselected FLASH participants consented to provide a fasted capillary blood sample for testing. In Spring 2011, 174 of those original participants returned to provide a follow-up 
sample. The final follow-up was conducted Spring 2012 when 149 of the original 204

returned.

Table 5. Dates of research fieldwork for each phase of the FLASH study (2009-2012).

\begin{tabular}{llllll}
\hline & $\begin{array}{l}\text { Online } \\
\text { survey }\end{array}$ & $\begin{array}{l}\text { Physical } \\
\text { Assessment }\end{array}$ & Heart Health & $\begin{array}{l}\text { Vitamin D } \\
\text { and Sun } \\
\text { Exposure }\end{array}$ & $\begin{array}{l}\text { Resting } \\
\text { Energy } \\
\text { Expenditure }\end{array}$ \\
\hline $\begin{array}{l}\text { Baseline } \\
\text { study, }\end{array}$ & $\mathrm{X}$ & $\mathrm{X}$ & 0 & 0 & 0 \\
$\begin{array}{l}\text { Fall } \\
2009\end{array}$ & $\mathrm{X}$ & $\mathrm{X}$ & 0 & $\mathrm{X}$ & 0 \\
$\begin{array}{l}\text { Spring } \\
2010\end{array}$ & $\mathrm{X}$ & $\mathrm{X}$ & $\mathrm{X}$ & $\mathrm{X}$ & 0 \\
$\begin{array}{l}\text { Fall } \\
2010\end{array}$ & $\mathrm{X}$ & $\mathrm{X}$ & $\mathrm{X}$ & 0 & $\mathrm{X}$ \\
$\begin{array}{l}\text { Spring } \\
2011\end{array}$ & $\mathrm{X}$ & $\mathrm{X}$ & $\mathrm{X}$ & $\mathrm{X}$ \\
$\begin{array}{l}\text { Spring } \\
2012\end{array}$ & $\mathrm{X}$ & $\mathrm{X}$ & $\mathrm{X}$ & 0 & $\mathrm{X}$ \\
\hline
\end{tabular}

\section{Survey}

The survey consisted of 6 sections and included 143 questions on sociodemographic information, health perceptions and lifestyle, physical activity and exercise habits, stress, dietary habits and dining patterns, and sun exposure and sun block use.

Table 6. Sections of the online FLASH survey

\begin{tabular}{ll}
\hline Section & Section Title \\
\hline I & $\begin{array}{l}\text { Socio-demographic } \\
\text { information } \\
\text { Health perceptions and } \\
\text { II }\end{array}$ \\
lifestyle \\
III & $\begin{array}{l}\text { Physical activity and } \\
\text { exercise habits }\end{array}$ \\
IV & Stress \\
V & Dietary habits and dining \\
& patterns \\
VI & Sun exposure and sun block \\
& use \\
\hline
\end{tabular}




\section{Measures}

Alcohol intake and alcohol consumption questions were asked in the health perceptions and lifestyle section of the FLASH survey created by the primary investigators Dr. Ann Yelmokas McDermott, PhD, MS, LDN (STRIDE, Kinesiology department) and Dr. Aydin Nazmi, PhD (Food Science and Nutrition) of California Polytechnic State University and administered by the Social Science Research Center of CSU Fullerton. The current study examined three questions regarding alcohol consumption as independent variables. Table 7 shows the full questions and possible responses. Alcohol frequency was determined by response to 'On how many days during the LAST 30 DAYS did you use: Alcohol'. Available answers were 'Have never used', 'Have used but not in the last 30 days', and 'Number of days used', with integers ranging from 1-30 to indicate number of days. The mean number of days alcohol was consumed was determined by the number of days reported among those who did report alcohol consumption. The average number of drinks consumed at an event or party was determined by the mean number of drinks consumed among those who reported having one drink or greater. Students reporting having so many they cannot remember and one student who reported consuming more than 20 drinks at an event determine mean drinks per event. Binge drinking was defined by reporting on how many days that five or more alcoholic drinks were consumed in one setting. Responses available were integers 1-30 or 'N/A (did not drink)'. 
Table 7. Survey questions regarding alcohol consumption

\begin{tabular}{|c|c|}
\hline Questions & Answer choices \\
\hline $\begin{array}{l}\text { 23. On how many days during the LAST } 30 \\
\text { DAYS did you use: Alcohol }\end{array}$ & $\begin{array}{l}\text { D Have never used } \\
\text { Have used but not in the last } 30 \text { days } \\
\text { Number of days as indicated by the } \\
\text { participant ranging from } 1-30 \text { days }\end{array}$ \\
\hline $\begin{array}{l}\text { 24. Within the last } 30 \text { days, approximately } \\
\text { how many times did you drink FIVE OR } \\
\text { MORE alcoholic drinks in one setting? }\end{array}$ & $\begin{array}{l}\square \text { N/A I don't drink } \\
\square \text { I drank, but never more than } 5 \text { drinks } \\
\text { on one occasion } \\
\square \text { Number of times as indicated by the } \\
\text { participant ranging from 1-31 times } \\
\square \text { More than } 31 \text { times }\end{array}$ \\
\hline $\begin{array}{l}\text { 25. At the last social event or party at which } \\
\text { alcohol was available, approximately how } \\
\text { many alcoholic drinks did you have? }\end{array}$ & $\begin{array}{l}\square \text { So many that I don't remember } \\
\square \text { N/A I did not drink } \\
\square \text { Number of drinks as indicated by the } \\
\text { participant ranging from 1-20 drinks } \\
\square \text { More than } 20 \text { drinks }\end{array}$ \\
\hline
\end{tabular}

\section{Coding}

Race/ethnic information was collected using a two-question system developed by the US Census. Race was determined by marking all that apply in response to 'what race do you consider yourself to be'. Options were: 1. American Indian of Alaska Native, 2. Asian, 3. Black or African American, 4. Native Hawaiian or Other Pacific Islander, or 5.White. African American, Native Hawaiian, and those reporting having two or more racial backgrounds were collapsed into one category due to small numbers in each. Ethnicity was defined as an individual identifying with either being Hispanic or Latino. Hispanic or Latino was defined as: A person of Mexican, Puerto Rican, Cuban, South or Central American, or other Spanish culture or origin, regardless of race. The term, "Spanish origin" can be used in addition to "Hispanic or Latino." 
Estimated annual household income was determined by categorical self-reported data of paternal and maternal income with seven selections: 1 . no income, 2. less than $\$ 10,000 /$ year, 3. \$10,000-24,999/year, 4. \$25,000-49,999/year, 5. \$50,000-74,999/year, 6. $\$ 75,000-\$ 100,000 /$ year, and 7. more than $\$ 100,000 /$ year. With each income range, the intermediate value was used as the estimate and annual household income was determined by summing values of both paternal and maternal income.

Stress was determined by responses from an inventory of 14 questions from the Perceived Stress Scale (PSS), as part of the online survey (Cohen, 1983). Five responses were available on a Likert scale ranging from never, almost never, sometimes, fairly often, and very often. The PSS has empirically shown adequate reliability of perceived stress (Cohen, 1983).

The questions about physical activity on the FLASH online survey were from the International Physical Activity Questionnaire (IPAQ). The questions asked participants to indicate the number days within the last 7 days that participants did vigorous physical activities and the number days within the last 7 days participants did moderate physical activities (answers were integers from 1-7 days or no moderate or vigorous physical activity). Vigorous physical activities were defined as activities that take hard physical effort and make you breathe much harder than normal. Moderate physical activities were defined as activities that take moderate physical effort and make you breathe somewhat harder than normal. Participants were then asked two additional questions to provide information about how much time was spent doing vigorous and moderate physical activities on the days indicated (answers were in hours from 1-10 whole number integers with 1 hour intervals and minutes ranged from 0-50 minutes with 10 minute intervals). 
From this data total minutes of vigorous physical activity (minutes vigorous physical activity*days) and moderate physical activity (minutes moderate physical activity*days) was calculated. Physical activity was assessed by using American College of Sports Medicine, ACSM, recommendations of 150 minutes of moderate intensity physical activity or 60 minutes of vigorous physical activity per week (Haskell et al., 2007). Physical activity was determined by either: $\geq 150$ minutes of moderate physical activity or $\geq 60$ minutes of vigorous physical activity or $\geq 120 \mathrm{~min}$ of combined moderate and vigorous physical activity.

Smoking was assessed by the number of days cigarettes were used within the last 30 days (responsive selections were: have never used, have used, but not in the last 30 days, and number of days cigarettes were used with integers ranging from 1-30). Nonsmokers were those who reported have never used cigarettes and those who have used but not within the last 30 days.

This study followed the definitions according to National Heart, Lung, and Blood Institute for body mass index (BMI) which defines underweight as a BMI of $<18.5$ $\mathrm{kg} / \mathrm{m}^{2}$, normal $18.5-24.9 \mathrm{~kg} / \mathrm{m}^{2}$, overweight $25-29.9 \mathrm{~kg} / \mathrm{m}^{2}$, and obese as having a BMI of $30 \mathrm{~kg} / \mathrm{m}^{2}$ or greater. BMI was calculated by self-reported height (inches) and weight (pounds) using BMI $=\left(\frac{\text { pounds }}{\text { inches }^{2}}\right) 703$. This study collapsed underweight and normal categories and defined a normal BMI as $18.5-24.9 \mathrm{~kg} / \mathrm{m}^{2}$. Overweight and obese categories were also collapsed and overweight was defined as having a BMI $25 \mathrm{~kg} / \mathrm{m}^{2}$ or greater. 


\section{Procedure for fasting blood glucose sampling}

Before coming to the appointment, participants were instructed to not eat or drink anything other than water for a minimum of 8 hours before testing. Before blood sampling participants were asked 'have you had anything to eat or drink in the last 8 hours, and the last 12 hours.' Participants were also asked 'when was the last time you had something to eat or drink other than water?'

Approximately 40 ul capillary blood was collected by finger prick with lancet and collected in $40 \mathrm{ul} \mathrm{heparin} \mathrm{coated} \mathrm{LDX} \mathrm{Capillary} \mathrm{Tubes} \mathrm{from} \mathrm{Care} \mathrm{Express} \mathrm{Products,} \mathrm{Inc.}$ Blood was transferred via plunger to Alere Lipid Profile-GLU cassettes and placed into Alere Cholestech LDX machines (Waltham, MA). The automated Cholestech LDX machine analyzed the blood samples using reflectance photometry.

\section{Technicians}

Fourteen research assistants plus three supervisors contacted original participants and administered finger prick, blood collection, and testing. All staff completed training in the National Health Institute Certification online course called "Protecting Human Research Participants", confidentiality protocols, study administration, finger prick technique, and Cholestech operations.

\section{Quality control}

Quality control measures included calibrating the Cholestech LDX machines at the start of each testing session according to manufacturer's specifications. A data entry team was responsible to secure the datasheets and enter the data into primary and secondary Access databases. Each datasheet was entered into the each respective 
database by a different data entry staff member. The tables from each database were exported to Microsoft Excel and the primary and secondary spreadsheets were compared using a VBA script which highlighted cells that were not identical in the primary and secondary spreadsheets. The data in the highlighted cells was then verified against the original datasheet to correct any possible data entry errors.

\section{Statistical analysis}

The current analysis examines cross-sectional data collected from April 2, 2012 May 11, 2012; during the FLASH Spring 2012 follow-up. Of the 149 participants, 141 had complete data. One-way analysis of variance (ANOVA) tests assessed the differences in fasting blood glucose levels according to categories of explanatory variables. Linear regression tests were used to compare differences between demographic and behavioral variables and fasting blood glucose.

Stepwise multiple linear regression models were constructed to adjust for confounding and mediating variables. Model 1 included race and ethnicity and dependent and independent variables. Model 2 included household income that may have acted as a potential confounder. Model 3 added behaviors such as cigarette use, physical activity, and stress level. Because obesity can elevate FBG, BMI is a suspected confounding variable and was adjusted for in Model 4. Statistical analysis was conducted using Stata 10.0 (College Station, Texas, USA).

All participants of the FLASH study and sub-studies provided written informed consent. All elements of the FLASH study were approved by the California Polytechnic State University Institutional Review Board. 


\section{CHAPTER 3}

\section{Results}

Fasting blood glucose and alcohol consumption patterns were collected from 141 student participants, 85 female and 56 male (Table 8). Ages of the students ranged from 20-22 years with the mean and (SD) of $20.2( \pm 0.45)$ years. White was the largest racial/ethnic group accounting for 104 of the participants. Thirteen students identified as Hispanic/Latino and 13 also identified as Asian. African American and students identifying with two or more races accounted for a total of 11 participants. Household income of greater than $\$ 150,000$ annually was the most prevalent income followed by 105,000-120,000. Equal prevalence was found among those with a household income of $\$ 87,500-\$ 96,500$ and $\$ 125,000-142,000$. Those reporting $\$ 50,000$ or less showed the least prevalence among participants.

Table 8. Percent or mean (SD) of descriptive socio-demographics ( $\mathrm{n}=141)$

\begin{tabular}{ll}
\hline Age & \\
20-22 years of age & $20.2 \pm 0.45$ \\
Sex & \\
Male & 39.7 \\
Female & 60.3 \\
Race/ Ethnicity & \\
Hispanic/ Latino & 9.2 \\
Asian & 9.2 \\
White & 73.8 \\
Other & 7.8 \\
Annual Household Income & \\
Up to 50,000 & 8.5 \\
62,500- 80,000 & 12.8 \\
$87,500-96,500$ & 16.3 \\
$105,000-120,000$ & 20.6 \\
$125,000-142,500$ & 16.3 \\
$150,000+$ & 25.5 \\
\hline
\end{tabular}


Descriptive socio-demographic variables are shown in Table 9. The average height and weight from self-reported data was $67.5( \pm 4.0)$ inches or 5 feet 7.5 inches and $147.7( \pm 26.8)$ pounds. The average BMI was found to be $22.7 \mathrm{~kg} / \mathrm{m}^{2}( \pm 3.1)$. Just over $80 \%$ of participants had a BMI of normal or underweight, whereas $17.7 \%$ had an overweight/obese BMI. The total perceived stress score ranged from 0-56 with a mean of $20.7( \pm 7.3)$. Seventy of the 141 participants met ACSM recommendations for physical activity. Four participants reported using cigarettes in the last 30 days. More than $62 \%$ of students $(n=88)$ reported alcohol consumption within the last 30 days. Fifty-three participants (37.9\%) reported not consuming any alcohol, and 84 participants $(60 \%)$ reported not binge drinking within the last 30 days. Among students who consumed alcohol at a social party or event, the average number of drinks consumed was $4.1 \pm 2.3$.

Table 9. Percent or mean (SD) of behavioral and anthropometric variables

\begin{tabular}{ll}
\hline Mean height, inches & $67.5 \pm 4.0$ \\
Mean weight, pounds & $147.7 \pm 26.8$ \\
Calculated mean BMI, kg/m² & $22.7 \pm 3.1$ \\
Normal $\leq 24.9$ & 80.9 \\
Overweight 25+ & 17.7 \\
Mean stress score & $20.7 \pm 7.3$ \\
Physical Activity & \\
$\quad$ Does not meet ACSM recommendations & 50.3 \\
$\quad$ Meets ACSM recommendations & 49.7 \\
Smoking & \\
Have not used cigarettes in past 30 days & 97.2 \\
$\quad$ Used cigarettes in past 30 days & 2.8 \\
Alcohol & 37.9 \\
$\quad$ Nondrinker & $4.4 \pm 3.1$ \\
$\quad$ \# of days of alcohol consumption & 60.0 \\
Non-Binge drinkers & $3.5 \pm 2.6$ \\
\# of days of binge drinking & $4.1 \pm 2.3$ \\
$\quad$ \# of drinks consumed at last party or event & \\
\hline
\end{tabular}

Table 10 shows $49 \%$ of males and $70 \%$ percent of female students reported drinking. Male students, who did drink, most commonly reported consuming alcohol 
between 3-5 days, over the past month, whereas most female students reported drinking between 1-2 days. Students who did report drinking in the last 30 days, prevalence of drinking was most reported drinking 1-5 days. Race/ethnicity had a significant association with alcohol consumption $(\mathrm{p}=0.05)$. White students reported higher frequency of alcohol consumption than other race/ethnicities, and were the only participants to consume alcohol on nine or more days on average. Hispanic/Latino had the highest prevalence of drinking followed by Other and White students had higher prevalence of drinking than Asian students. Household income did not show a significant association with alcohol frequency. Smoking was found to have a significant association on number of days alcohol was consumed where smokers $(n=4)$ were found to consume alcohol between 3-13 days per month $(\mathrm{p}=0.03)$. No significant association was found between alcohol consumption over the past month with BMI, stress, or physical activity. 
Table 10. Percent frequency of alcohol consumption according to socio-demographic variables and behavioral patterns in past 30 days

\begin{tabular}{|c|c|c|c|c|c|c|}
\hline & 0 days & $\begin{array}{l}1-2 \\
\text { days }\end{array}$ & $\begin{array}{l}3-5 \\
\text { days }\end{array}$ & $\begin{array}{l}6-8 \\
\text { days }\end{array}$ & $\begin{array}{l}9-13 \\
\text { days }\end{array}$ & $\begin{array}{l}\mathrm{p}- \\
\text { value }\end{array}$ \\
\hline Total \% & 37.9 & 21.4 & 22.1 & 9.3 & 9.3 & \\
\hline Sex & & & & & & 0.08 \\
\hline Male & 50.9 & 14.6 & 18.2 & 5.4 & 10.9 & \\
\hline Female & 29.4 & 25.9 & 24.7 & 11.8 & 8.24 & \\
\hline Race/ Ethnicity & & & & & & 0.05 \\
\hline Hispanic/ Latino & 38.5 & 30.8 & 7.7 & 23.1 & 0.0 & \\
\hline Asian & 69.2 & 15.4 & 7.7 & 7.7 & 0.0 & \\
\hline White & 33.7 & 18.3 & 26.9 & 8.7 & 12.5 & \\
\hline Other & 40.0 & 50.0 & 10.0 & 0.0 & 0.0 & \\
\hline Household Income & & & & & & 0.08 \\
\hline Up to 50,000 & 41.7 & 8.3 & 41.7 & 8.3 & 0.0 & \\
\hline $62,500-80,000$ & 38.9 & 5.6 & 11.1 & 27.8 & 16.7 & \\
\hline $87,500-96,500$ & 34.8 & 39.1 & 21.7 & 4.4 & 0.0 & \\
\hline $105,000-120,000$ & 41.4 & 13.8 & 31.0 & 3.5 & 10.3 & \\
\hline $125,000-142,500$ & 26.1 & 30.4 & 26.1 & 4.4 & 13.0 & \\
\hline $150,000+$ & 42.9 & 22.9 & 11.4 & 11.4 & 11.4 & \\
\hline Smoking & & & & & & 0.03 \\
\hline Nonsmoker & 39.0 & 22.1 & 22.1 & 8.1 & 8.8 & \\
\hline Smoker & 0.0 & 0.0 & 25 & 50.0 & 25.0 & \\
\hline $\mathrm{BMI} \mathrm{kg/ \textrm {m } ^ { 2 }}$ & & & & & & 0.5 \\
\hline Normal $\leq 24.9$ & 38.1 & 21.2 & 24.8 & 8.0 & 8.0 & \\
\hline Overweight $25+$ & 36 & 24.0 & 12.0 & 16.0 & 12.0 & \\
\hline Stress score & & & & & & 0.3 \\
\hline Low & 31.8 & 15.9 & 25.0 & 9.1 & 18.2 & \\
\hline Moderate & 34.9 & 23.3 & 27.9 & 7.0 & 7.0 & \\
\hline High & 47.6 & 26.2 & 16.7 & 4.8 & 4.8 & \\
\hline Physical Activity & & & & & & 0.8 \\
\hline $\begin{array}{l}\text { Does not meet ACSM } \\
\text { recommendations }\end{array}$ & 42.3 & 19.7 & 19.7 & 8.5 & 9.9 & \\
\hline Meets ACSM recommendations & 33.3 & 23.2 & 24.6 & 10.1 & 8.7 & \\
\hline
\end{tabular}

P-values by chi-square analysis.

No association between binge drinking and socio-demographic variables was found to be statistically significant (Table 11). More female students (42.3\%) reported binge drinking compared to males $(37.5 \%)(\mathrm{p}=0.6)$, however, nearly double the amount of males binged six or more times within the last 30 days. Binge drinking was most reported by Hispanic/Latino students followed by White students. Forty-three percent of 
those classified as Other reported binge drinking and one Asian student (7.7\%) reported binge drinking $(\mathrm{p}=0.2)$. Hispanic/Latino and White students were the only racial group to report binge drinking on six or more days. Household income did not show significant association on binge drinking $(\mathrm{p}=0.8)$. However, students in the lowest income category (up to $\$ 50,000$ ) and $\$ 87,500-\$ 96,500$ did not report binge drinking on six or more days. All smokers $(n=4)$ reported binge drinking between 1-5 days within the last 30 days; and $39 \%$ of non-smokers did not report binge drinking $(\mathrm{p}=0.005)$. BMI $(\mathrm{p}=0.4)$, stress $(\mathrm{p}=0.2)$, and physical activity $(\mathrm{p}=0.7)$ did not show significant trends influencing the prevalence of binge drinking. 
Table 11. Frequency of binge drinking during one sitting according to sociodemographic variables and behavioral patterns in past 30 days

\begin{tabular}{|c|c|c|c|c|c|}
\hline & 0 Times & $\begin{array}{l}1-2 \\
\text { Times }\end{array}$ & $\begin{array}{l}3-5 \\
\text { Times }\end{array}$ & $\begin{array}{l}6+ \\
\text { Times }\end{array}$ & p-value \\
\hline Sex & & & & & 0.6 \\
\hline Male & 62.5 & 16.1 & 12.5 & 8.9 & \\
\hline Female & 57.7 & 21.2 & 16.5 & 4.71 & \\
\hline Race/ Ethnicity & & & & & 0.2 \\
\hline Hispanic/ Latino & 46.2 & 38.5 & 7.7 & 7.7 & \\
\hline Asian & 92.3 & 0.0 & 7.7 & 0.0 & \\
\hline White & 56.7 & 18.3 & 17.3 & 7.7 & \\
\hline Other & 63.6 & 27.3 & 9.1 & 0.0 & \\
\hline Household Income & & & & & 0.8 \\
\hline Up to 50,000 & 66.7 & 16.7 & 16.7 & 0.0 & \\
\hline $62,500-80,000$ & 44.4 & 22.2 & 16.7 & 16.7 & \\
\hline $87,500-96,500$ & 69.6 & 8.7 & 21.7 & 0.0 & \\
\hline $105,000-120,000$ & 65.5 & 20.7 & 10.3 & 3.5 & \\
\hline $125,000-142,500$ & 56.5 & 21.7 & 13.0 & 8.7 & \\
\hline $150,000+$ & 55.6 & 22.2 & 13.9 & 8.3 & \\
\hline Smoking & & & & & 0.005 \\
\hline Nonsmoker & 61.3 & 19.0 & 13.1 & 6.6 & \\
\hline Smoker & 0.0 & 25.0 & 75.0 & 0.0 & \\
\hline BMI kg/m² & & & & & 0.4 \\
\hline Normal $\leq 24.9$ & 60.5 & 17.5 & 16.7 & 5.3 & \\
\hline Overweight $25+$ & 56.0 & 24.0 & 8.0 & 12.0 & \\
\hline Stress score & & & & & 0.2 \\
\hline Low & 51.1 & 24.4 & 13.3 & 11.1 & \\
\hline Moderate & 60.5 & 16.3 & 18.6 & 4.7 & \\
\hline High & 71.4 & 19.1 & 9.5 & 0.0 & \\
\hline Physical Activity & & & & & 0.7 \\
\hline Does not meet ACSM & 62.0 & 15.5 & 15.5 & 7.0 & \\
\hline recommendations & 57.1 & 22.9 & 14.3 & 5.7 & \\
\hline Meets ACSM recommendations & & & & & \\
\hline
\end{tabular}

Females were found to have significantly lower FBG values when compared to males $80.3 \mathrm{mg} / \mathrm{dl} \pm 6.8$ and $85.9 \mathrm{mg} / \mathrm{dl} \pm 7.6$ respectively, $\mathrm{p}=0.0001$ (Table 12).

Race/ethnicity had a significant association on FBG. Hispanic/Latino and Other students had the lowest FBG levels, $78.5 \mathrm{mg} / \mathrm{dl}$ and $79.7 \mathrm{mg} / \mathrm{dl}$; followed by White students 
$82.8 \mathrm{mg} / \mathrm{dl}$. Asian students had the highest FBG values of $86.8 \mathrm{mg} / \mathrm{dl}$. Household income did not show a significant association with FBG levels $(p=0.5)$.

Table 12. Fasting blood glucose by socio-demographic characteristics

\begin{tabular}{lll}
\hline & FBG, mg/dl & p-value \\
\hline Sex & $85.9 \pm 7.6$ & $<0.0001$ \\
Male & $80.3 \pm 6.8$ & \\
Female & & 0.02 \\
Race/ Ethnicity & $78.5 \pm 4.9$ & \\
Hispanic/ Latino & $86.8 \pm 6.8$ & \\
Asian & $82.8 \pm 7.7$ & \\
White & $79.7 \pm 8.4$ & \\
Other & & \\
Household Income & $84.5 \pm 6.8$ & \\
Up to 50,000 & $85.0 \pm 7.2$ & \\
62,500- 80,000 & $81.8 \pm 8.1$ & \\
87,500- 96,500 & $82.8 \pm 8.8$ & \\
105,000-120,000 & $80.7 \pm 6.2$ & \\
125,000-142,500 & $82.2 \pm 7.6$ & \\
150,000+ & & \\
\hline
\end{tabular}

P-values by ANOVA test.

BMI was also observed to be associated with FBG $(\mathrm{p}=0.001)$ (Table 13), where students with a normal BMI had significantly lower FBG levels than students with an overweight BMI. Smoking, stress, and physical activity, did not have an association with FBG. 
Table 13. Fasting blood glucose according to behavioral patterns

\begin{tabular}{lll}
\hline & FBG $(\mathrm{mg} / \mathrm{dl})$ & $\mathrm{p}$-value \\
\hline Smoking & & 0.4 \\
$\quad$ Nonsmoker & $82.6 \pm 7.6$ & \\
$\quad$ Smoker & $79.5 \pm 7.9$ & \\
BMI & & 0.001 \\
$\quad$ Normal $\leq 24.9$ & $81.6 \pm 6.8$ & \\
$\quad$ Overweight 25+ & $87.1 \pm 9.5$ & \\
Stress score & & 0.8 \\
$\quad$ Low & $82.6 \pm 7.3$ & \\
$\quad$ Moderate & $83.0 \pm 8.9$ & \\
$\quad$ High & $82.0 \pm 7.1$ & \\
Physical Activity & & $>0.9$ \\
$\quad$ Does not meet ACSM recommendations & $82.5 \pm 8.1$ & \\
$\quad$ Meets ACSM recommendations & $82.6 \pm 7.1$ & \\
\hline
\end{tabular}

P-values by independent t-test and ANOVA analysis.

Alcohol consumption had a significant effect on FBG ( $\mathrm{p}=0.04)$ (Table 14). Lowest FBG were found among students who consumed alcohol 6-8 days $(79.9 \mathrm{mg} / \mathrm{dl} \pm 7.8)$ followed by students who consumed alcohol 3-5 days and students 1-2 days had FBG values of $80.6 \mathrm{mg} / \mathrm{dl} \pm 6.3$ and $81.1 \mathrm{mg} / \mathrm{dl} \pm 7.9$, respectively. Students who consumed alcohol on nine or greater days, had the highest FBG of $86.1 \mathrm{mg} / \mathrm{dl} \pm 6.6$.

Table 14. Fasting blood glucose and frequency of drinking within last 30 days

\begin{tabular}{lcccccc}
\hline & 0 Days & 1-2 Days & 3-5 Days & 6-8 Days & 9-13 Days & p-value \\
\hline $\begin{array}{l}\text { FBG } \\
\mathrm{mg} / \mathrm{dl}\end{array}$ & $84.1 \pm 7.8$ & $81.1 \pm 7.9$ & $80.6 \pm 6.3$ & $79.9 \pm 7.8$ & $86.1 \pm 6.6$ & 0.04 \\
\hline \multicolumn{2}{l}{ P-value by ANOVA analysis. }
\end{tabular}

Students who reported binge drinking between 1-2 times within the last month had the lowest FBG of $81.3 \mathrm{mg} / \mathrm{dl} \pm 6.8$ followed by students who binged 3-5 times (81.6 \pm 6.1 ) (Table 15). Students who binged six or more times had higher FBG than students who did not binge and students who binged less than six days. Frequency of binge drinking, however, was not significantly associated with FBG $(\mathrm{p}=0.4)$. 
Table 15. Fasting blood glucose and binge drinking within last 30 days

\begin{tabular}{llllll}
\hline & 0 Times & 1-2 Times & 3-5 Times & 6+ Times & p-value \\
\hline FBG mg/dl & $82.8 \pm 8.0$ & $81.3 \pm 6.8$ & $81.6 \pm 6.1$ & $85.9 \pm 9.5$ & 0.4 \\
\hline
\end{tabular}

P-value by ANOVA analysis.

The unadjusted model found significant differences in FBG according to frequency of alcohol consumption, sex, race/ethnicity, and BMI (Table 16). Students who consumed alcohol between 3-5 days showed significantly lower FBG -3.5 (-6.8,-0.2) compared to those who did not consume alcohol. Other frequencies of alcohol consumption did not show significant effects. Female students were found to have significantly lower FBG -5.6 (-8.0,-3.2) compared to males. Asian students had significantly higher FBG $(8.4(2.6,14.2)$ compared to Hispanic/Latino students. Students with an overweight BMI had significantly higher FBG than students with a BMI in the normal range $5.4(2.2,8.6)$. Household income, stress, physical activity, and smoking did not have a significant effect on FBG in the unadjusted model.

Significant differences were found when adjusted for sex and race (Model 1). Female students showed a lower FBG of $-4.3(-6.8,-1.8)$ than male students. Asian students had a higher FBG of $6.5(1.0,12.0)$ compared to Hispanic/Latino students. No significant difference was found among frequency of alcohol consumption and FBG when adjusted for sex and race.

Adjusting for household income (Model 2) showed no significant difference among alcohol consumption and FBG. Female students were found to have significantly lower FBG than male students -4.4 (-6.8,-1.7). Marginal association was found among Asian students, $5.6(-0.1,11.3)$, however no significant difference was found with race/ethnicity. 
Model 3 includes adjustment for behavioral variables; stress, smoking, and physical activity. Frequency of alcohol consumption did not have a significant association with FBG; however, sex was associated with FBG. Female students had a lower FBG of -4.4 (-7.2,-1.6) compared to male students. Model 3 also showed a marginal association among Asian students, $5.8(-0.7,12.2)$, though not significant. Household income, stress, smoking, and physical activity did not have a significant association effect on FBG.

Model 4 adjusted for socio-demographic variables, behavior variables, and BMI. Female students and BMI were found to have significant associations on FBG. Female students were found to have a lower FBG of $-3.5(-6.4,-0.6)$ compared to male students. Students with an overweight BMI were found to have a significantly higher FBG of 3.7 $(0.3,7.1)$. No significant difference was found on FBG among frequency of alcohol consumption, race/ ethnicity, household income, stress, physical activity, and smoking. 
Table 16. Unadjusted and four sequentially adjusted linear regression models beta (95\% CI) for associations with fasting blood glucose $(\mathrm{mg} / \mathrm{dl})$, with the number of days alcohol consumed as the primary exposure variable.

\begin{tabular}{|c|c|c|c|c|c|}
\hline & Unadjusted & $\begin{array}{l}\text { Model 1: } \\
\text { sex, race }\end{array}$ & $\begin{array}{l}\text { Model 2: } \\
+\mathrm{HH} \text { income }\end{array}$ & $\begin{array}{l}\text { Model 3: } \\
+ \text { stress, } \\
\text { smoking, PA }\end{array}$ & $\begin{array}{l}\text { Model 4: } \\
+ \text { BMI }\end{array}$ \\
\hline \multicolumn{6}{|l|}{$\begin{array}{l}\text { \# of Days Alcohol } \\
\text { consumed in Last } \\
30 \text { days }\end{array}$} \\
\hline 0 days & Ref & Ref & Ref & Ref & Ref \\
\hline 1-2 days & $-3.0(-6.3,0.4)$ & $-1.0(-4.3,2.2)$ & $-0.7(-4.1,2.6)$ & $-1.2(-4.9,2.4)$ & $-2.1(-5.8,1.5)$ \\
\hline 3-5 days & $-3.5(-6.8,-0.2)^{*}$ & $-2.5(-5.7,0.7)$ & $-2.6(-5.9,0.7)$ & $-3.0(-6.7,0.6)$ & $-3.3(-6.9,0.3)$ \\
\hline 6-8 days & $-4.1(-8.7,0.4)$ & $-2.4(-6.8,2.0)$ & $-2.8(-7.3,1.8)$ & $3.3(-9.3,2.6)$ & $-4.4(-10.3,1.4)$ \\
\hline 9-13 days & $2.0(-2.5,6.6)$ & $2.3(-2.1,6.6)$ & $2.4(-2.1,6.9)$ & $2.6(-2.2,7.5)$ & $1.8(-3.1,6.7)$ \\
\hline \multicolumn{6}{|l|}{ Sex } \\
\hline Male & Ref & Ref & Ref & Ref & Ref \\
\hline Female & $-5.6(-8.0,-3.2)^{*}$ & $-4.3(-6.8,-1.8)^{*}$ & $-4.4(-6.8,-1.7)^{*}$ & $-4.4(-7.2,-1.6)^{*}$ & $-3.5(-6.4,-0.6)^{*}$ \\
\hline \multicolumn{6}{|l|}{ Race } \\
\hline Asian & $8.4(2.6,14.2)^{*}$ & $6.5(1.0,12.0)^{*}$ & $5.6(-0.1,11.3)$ & $5.8(-0.7,12.2)$ & $5.3(-1.1,11.7)$ \\
\hline Hispanic/Latino & Ref & Ref & Ref & Ref & Ref \\
\hline White & $4.4(0.0,8.7)^{*}$ & $3.3(-0.9,7.5)$ & $2.8(-1.5,7.1)$ & $2.8(-2.4,8.1)$ & $2.6(-2.6,7.8)$ \\
\hline Other & $1.3(-4.8,7.3)$ & $-0.5(-6.4,5.3)$ & $-0.7(-6.7,5.3)$ & $0.2(-6.7,7.1)$ & $0.0(-6.8,6.8)$ \\
\hline \multicolumn{6}{|l|}{ Household Income } \\
\hline Up to 50,000 & Ref & & Ref & Ref & Ref \\
\hline $62,500-80,000$ & $0.5(-5.1,6.1)$ & -- & $-0.5(-5.9,4.8)$ & $-1.1(-6.7,4.6)$ & $0.8(-6.3,4.8)$ \\
\hline $87,500-96,500$ & $-2.7(-8.1,2.7)$ & & $-2.1(-7.2,3.0)$ & $-2.2(-7.7,3.3)$ & $-1.3(-6.8,6.8)$ \\
\hline $105,000-120,000$ & $-1.7(-6.9,3.5)$ & & $-1.5(-6.3,3.4)$ & $-1.2(-6.2,3.9)$ & $-1.2(-6.2,3.8)$ \\
\hline $125,000-142,500$ & $-3.8(-9.2,1.5)$ & & $-3.0(-8.1,2.1)$ & $-3.5(-8.9,2.0)$ & $-3.1(-8.5,2.4)$ \\
\hline $150,000+$ & $-2.3(-7.4,2.7)$ & & $-2.5(-7.3,2.3)$ & $-2.5(-7.7,2.7)$ & $-2.3(-7.4,2.8)$ \\
\hline Stress score & & -- & -- & & \\
\hline Low & Ref & & & Ref & Ref \\
\hline Moderate & $0.4(-2.9,3.7)$ & & & $1.6(-1.6,4.8)$ & $1.5(-1.7,4.7)$ \\
\hline High & $-0.6(-3.9,2.7)$ & & & $0.4(-3.0,3.8)$ & $0.1(-3.3,3.5)$ \\
\hline $\begin{array}{l}\text { Meets ACSM } \\
\text { recommendations } \\
\text { for Physical }\end{array}$ & -- & -- & -- & & \\
\hline \multicolumn{6}{|l|}{ Activity } \\
\hline No & Ref & & & Ref & Ref \\
\hline Yes & $0.1(-2.5,2.6)$ & & & $0.3(-2.4,2.9)$ & $0.6(-2.1,3.2)$ \\
\hline Smoking & & -- & -- & & \\
\hline No $n=137$ & Ref & & & Ref & Ref \\
\hline Yes $n=4$ & $-3.1(-10.8,4.5)$ & & & $-0.7(-8.3,8.2)$ & $0.7(-7.4,8.8)$ \\
\hline BMI kg/m ${ }^{2}$ & & -- & -- & -- & \\
\hline Normal $\leq 24.9$ & Ref & & & & Ref \\
\hline Overweight 25+ & $5.4(2.2,8.6)^{*}$ & & & & $3.7(0.3,7.1)^{*}$ \\
\hline
\end{tabular}

*Indicates statistical significance.

In the unadjusted model binge drinking did not have a significant association on

FBG (Table 17). Model 1 was adjusted for sex and race. A significant difference was 
found in female students, having a lower FBG -5.0 (-7.4,-2.5) than male students. Asian students were found to have a significantly higher FBG than Hispanic/Latino students 7.0 $(1.3,12.7)$.

Similarly, when adjusting for household income (Model 2) female students had a significantly lower FBG than male students -4.9 (-7.4,-2.4). Asian students had a significantly higher FBG than Hispanic/Latino students $6.3(0.3,12.2)$. No significant effect was found among binge drinking and household income.

No significant effect was found on FBG and binge drinking when adjusting for behavioral variables; stress, smoking, and physical activity, as well as race/ethnicity and income (Model 3). Female students had a lower FBG compared to male students -5.3 ($8.2,-2.6)$

Sex was the only significant difference found when adjusting for BMI along with socio-demographic and behavioral adjustments (Model 4). No significant effect was found among binge drinking and race/ethnicity, household income, stress, physical activity, smoking, and BMI. 
Table 17. Unadjusted and four sequentially adjusted linear regression models Beta (95\% CI) for associations with fasting blood glucose $(\mathrm{mg} / \mathrm{dl})$, with the number of days of binge drinking as the primary exposure variable.

\begin{tabular}{|c|c|c|c|c|c|}
\hline & $\begin{array}{l}\text { Unadjusted } \\
\text { analyses }\end{array}$ & $\begin{array}{l}\text { Model 1: } \\
\text { sex, race }\end{array}$ & $\begin{array}{l}\text { Model 2: } \\
+\mathrm{HH} \text { income }\end{array}$ & $\begin{array}{l}\text { Model 3: } \\
+ \text { stress, } \\
\text { smoking, PA }\end{array}$ & $\begin{array}{l}\text { Model 4: } \\
+ \text { BMI }\end{array}$ \\
\hline \multicolumn{6}{|l|}{$\begin{array}{l}\# \text { of days of binge } \\
\text { drinking in last } 30 \\
\text { days }\end{array}$} \\
\hline 0 days & Ref & Ref & Ref & Ref & Ref \\
\hline 1-2 days & $-1.5(-4.8,1.9)$ & $-0.1(-3.3,3.1)$ & $-0.2(-3.5,3.1)$ & $0.0(-3.6,3.5)$ & $-0.8(-4.4,2.8)$ \\
\hline 3-5 days & $-1.3(-4.9,2.4)$ & $-0.7(-4.1,2.8)$ & $-0.7(-4.2,2.8)$ & $-0.2(-4.4,4.0)$ & $0.0(-4.2,4.1)$ \\
\hline $6+$ & $3.1(-2.2,8.4)$ & $2.8(-2.1,7.8)$ & $2.8(-2.4,8.0)$ & $2.5(-3.7,8.6)$ & $2.1(-4.0,8.2)$ \\
\hline \multicolumn{6}{|l|}{ Sex } \\
\hline Male & Ref & Ref & Ref & Ref & Ref \\
\hline Female & $-5.6(-8.0,-3.2)^{*}$ & $-5.0(-7.4,-2.5)^{*}$ & $-4.9(-7.4,-2.4)^{*}$ & $-5.3(-8.2,-2.6)^{*}$ & $-4.8(-7.6,-2.0)^{*}$ \\
\hline \multicolumn{6}{|l|}{ Race } \\
\hline Asian & $8.4(2.6,14.2)^{*}$ & $7.0(1.3,12.7)^{*}$ & $6.3(0.3,12.2)^{*}$ & $6.1(-0.8,13.0)$ & $5.3(-1.6,12.1)$ \\
\hline Hispanic/Latino & Ref & Ref & Ref & Ref & Ref \\
\hline White & $4.4(0.0,8.7)^{*}$ & $3.5(-0.7,7.7)$ & $3.1(-1.2,7.5)$ & $2.9(-2.6,8.3)$ & $2.3(-3.1,7.7)$ \\
\hline Other & $1.3(-4.8,7.3)$ & $1.3(-4.5,7.0)$ & $1.2(-4.7,7.1)$ & $1.9(-5.0,8.8)$ & $1.6(-5.2,8.4)$ \\
\hline \multicolumn{6}{|l|}{ Household Income } \\
\hline Up to 50,000 & Ref & & Ref & Ref & Ref \\
\hline $62,500-80,000$ & $0.5(-5.1,6.1)$ & & $0.4(-5.8,5.0)$ & $-0.3(-6.1,5.4)$ & $-0.1(-5.8,5.6)$ \\
\hline $87,500-96,500$ & $-2.7(-8.1,2.7)$ & & $-1.7(-6.8,3.5)$ & $-1.6(-7.1,4.0)$ & $-1.1(-6.6,4.4)$ \\
\hline $105,000-120,000$ & $-1.7(-6.9,3.5)$ & & $-1.1(-6.0,3.8)$ & $-0.6(-9.1,7.9)$ & $-0.6(-5.7,4.6)$ \\
\hline $125,000-142,500$ & $-3.8(-9.2,1.5)$ & & $-2.6(-7.7,2.6)$ & $-2.7(-8.3,2.8)$ & $-2.4(-7.8,3.1)$ \\
\hline $150,000+$ & $-2.3(-7.4,2.7)$ & & $-1.6(-6.5,3.2)$ & $-1.5(-6.8,3.7)$ & $-1.6(-6.8,3.6)$ \\
\hline Stress score & & - & - & & \\
\hline Low & Ref & & & Ref & Ref \\
\hline Moderate & $0.4(-2.9,3.7)$ & & & $1.2(-2.1,4.5)$ & $1.2(-2.1,4.5)$ \\
\hline High & $-0.6(-3.9,2.7)$ & & & $0.6(-2.9,4.0)$ & $0.4(-3.0,3.9)$ \\
\hline $\begin{array}{l}\text { Meets ACSM } \\
\text { recommendations } \\
\text { for Physical }\end{array}$ & & - & - & & \\
\hline \multicolumn{6}{|l|}{ Activity } \\
\hline No & Ref & & & Ref & Ref \\
\hline Yes & $0.1(-2.5,2.6)$ & & & $0.0(-2.8,2.7)$ & $0.2(-2.6,2.9)$ \\
\hline Smoking & & - & - & & \\
\hline No $n=137$ & Ref & & & Ref & Ref \\
\hline Yes $n=4$ & $-3.1(-10.8,4.5)$ & & & $-0.6(-9.1,7.9)$ & $-0.5(-8.8,7.9)$ \\
\hline BMI kg/m ${ }^{2}$ & & - & - & - & \\
\hline Normal $\leq 24.9$ & Ref & & & & Ref \\
\hline Overweight 25+ & $5.4(2.2,8.6)^{*}$ & & & & $3.5(0.0,7.0)$ \\
\hline
\end{tabular}

*Indicates statistical significance. 


\section{CHAPTER 4}

\section{Discussion}

This study analyzed the associations between alcohol consumption and fasting blood glucose levels in young adults. Frequency of alcohol consumption was determined by number of days alcohol was consumed through self-reported survey and blood glucose was measured with capillary blood after a minimum eight hour fast. We found a significant difference in FBG and alcohol consumption among young adults (Table 14). Young adults consuming alcohol between 3-5 days within the past month had significantly lower fasting glucose concentrations $(-3.5[-6.8,-0.2])$ in blood compared to students who did not report alcohol consumption within the last month and those who reported drinking more (Table 16). This supports findings that moderate alcohol consumption is associated with lower fasting blood glucose concentrations and may reduce the risk for developing type II diabetes.

Alcohol consumption showed a significant association on FBG levels $(\mathrm{p}=0.04)$ and resulted in a $\mathbf{J}$ - shaped curve where those consuming alcohol between 6-8 days showed the lowest FBG values, of $79.9 \mathrm{mg} / \mathrm{dl} \pm 7.8$, compared to students who did not drink and students who reported drinking between 9-13 days within the last 30 days showed the highest values of FBG, $86.1 \mathrm{mg} / \mathrm{dl} \pm 6.6$ (Table 14). Additionally, students who reported drinking 3-5 days per month had significantly lower FBG compared to students who did not drink -3.5 (-6.8,-0.2) (Table 16). Students who reported alcohol consumption between 1-8 days within the last 30 days had a lower mean FBG compared to those who did not drink alcohol and those who consumed alcohol on nine or more days. These results indicate that FBG declines with increasing the number of days alcohol was consumed when compared to those who did not drink, however, a turning point is 
observed where FBG levels raise again when alcohol is consumed after the 6-8 day threshold.

Consuming alcohol on 6-8 days within 30 days approximately is equivalent to drinking alcohol 1.5-2 times per week. Similarly Wannamethee et al., (2003), also found those who consumed alcohol 1-3 days per week decreased relative risk of developing type II diabetes to $0.29(0.09-0.91)$. However this study found those consuming alcohol between 4-7 days/week had the lowest risk of developing type II diabetes compared to non-drinkers and infrequent drinkers. Those consuming alcohol 4-7 days/week decreased their risk to 0.62 (95\% CI 0.23-1.68).

We found students who consumed alcohol between 3-5 and 6-8 days/month had significantly lower levels of FBG. If four is the average number of days alcohol was consumed in the last 30 days then this can be measured as approximately once per week. Koppes et al., (2005) found individuals consuming $\leq 6 \mathrm{~g} /$ day (or about 2.94 drinks per week), had lower relative risk of developing type II diabetes, 0.87 (95\% CI 0.79-0.95). Those consuming $\geq 48 \mathrm{~g} /$ day or approximately 96 drinks per month had a relative risk of type II diabetes similar to those not consuming alcohol, 1.04 (95\% CI 0.84-1.29). Baliunas et al., (2009) found men who reported consuming 4.3 drinks/day and women who reported consuming 3.6 drinks/day had increased their relative risk for diabetes, 1.01 (95\% CI 0.71-1.44), and 1.02 (95\% CI 0.83-1.26).

Students who did not report drinking had higher FBG than students who did report alcohol consumption. Though these levels were still considered Normal by the American Diabetes Association, a higher FBG concentration can increase future risk of diabetes later in life. 
Examining the association of binge drinking, students reported an average frequency of binge drinking of $3.5 \pm 2.6$ times per month (Table 9). Our data shows binge drinking was slightly lower than other literature. National data shows $43.1 \%$ of men binge drink as opposed to $21.9 \%$ of women (SAMHSA 2012, Johnston et al., 2010). Similarly, our findings show $40.0 \%$ of all students, $37.5 \%$ of males and $42.3 \%$ of females reported binge drinking. Johnston et al., (2010) found males reported binge drinking 2.25 times in the past two weeks, or approximately 4.5 times within the last month and females reported 1.7 times/week, or 3.4 times within the last month. We found both males and females who binged most frequently reported 1-2 times within the last 30 days (Table 11). Interestingly, we found more female students reported binge drinking than male students, but more than twice as many male students reported drinking six or more times within the last 30 days.

Binge drinking was not found to be associated with FBG (Table 15). Those who reported binge drinking between 1-5 days had the lowest levels of FBG. Students binging between 1-2 days had a FBG of $81.3 \mathrm{mg} / \mathrm{dl} \pm 6.8$ and students binging between 3-5 days had a FBG of $81.6 \mathrm{mg} / \mathrm{dl}$ units? $\pm 6.1(\mathrm{p}=0.4)$. The unadjusted model in Table 17 shows those binge drinking between 1-2 days had a lower FBG by $-1.5 \mathrm{mg} / \mathrm{dl}(-4.8,1.9)$ compared to those who did not binge drink; whereas students who reported binge drinking on six or more days had higher FBG by $3.1 \mathrm{mg} / \mathrm{dl}(-2.2,8.4)$. This finding is consistent with previous research that showed that excessive alcohol consumption can reduce insulin sensitivity and therefore increase glucose concentrations in the blood (Athyros et al., 2008). 
In addition to frequency of alcohol consumption, we found sex and BMI to also have a significant association with FBG. Our study found females had significantly lower FBG compared to males across all models. This is also consistent with literature findings and physiological mechanisms in which women tend to have higher levels of insulin in the blood (CDC, 2011, Dunstan et al., 2002; Flanagan et al., 2000, Cowie et al., 2006). This higher plasma insulin concentration contributes to the decreased insulin sensitivity seen among women (Baliunas et al., 2009). Data suggests men have a higher risk of having above normal FBG than women (Juonala et al., 2010).

BMI was shown to have significant effect on FBG levels, $\mathrm{p}=0.001$ (Table 12). Physiologically, adipose tissue can induce inflammation which can reduce insulin sensitivity, thus keeping FBG chronically at a higher level giving us cause to adjust for BMI in Model 4 (Kalupahana et al., 2012). The national average for 20-29 year olds is $26.8 \pm 0.3$ for males and $27.9 \pm 0.1$ for females (Ogden, Fryer, Carroll, \& Flegal et al., 2004). The average BMI of participants was $22.7 \mathrm{~kg} / \mathrm{m}^{2}$, which is considered normal. Alcohol consumption of this subsample of Cal Poly students seems highly consistent with existing literature. It was found that just over $62 \%$ of the participants reported drinking within the last 30 days, consistent with national data that $61 \%$ of $18-25$ year olds have used alcohol within the last month (SAMHSA, 2012). We also found that $40 \%$ of students reported binge drinking, consistent with findings from Johnston et al., (2010) who also found $40 \%$ of college students report binge drinking.

Four was the mean number of drinks consumed at a social party or event among students who reported. Similarly, national data found during events where alcohol was 
consumed $42 \%$ of men reported drinking four or more drinks. In contrast, $48 \%$ of women report having only one drink per event (SAMHSA, 2012).

\section{Discussion of socio-demographic variables}

The average age of each participant was 20.2 years old which represents the mean age of all Cal Poly students according to Fall 2011 Cal Poly demographic data (Table 8) (Cal Poly, 2012). Interestingly, more participants were female, unusual since $54 \%$ of the Cal Poly students are male $(n=10,400)$ and $46 \%$ female $(n=8,362)$. This may be because women are more likely to include preventative health behaviors in their lives than men, which may also lead to increased participation in related activities such as health and wellness surveys (Courtenay, 2000).

Results were consistent with data from literature in that White students reported higher frequency of alcohol consumption than other races (Table 10). Our data showed White students were the only students $(n=13)$ who consumed alcohol on nine or more days in the past 30 days. Over 54\% ( \pm 0.48$)$ of Whites are regular consumers, and had the largest percentage of regular consumers and the lowest percentage of lifetime abstainers $17.3 \%( \pm 0.37)$ compared to other race/ethnicities (CDC, 2011a). .

Our data shows a significant difference among race/ethnic groups and FBG $(\mathrm{p}=0.02)$ (Table 12). We found Asian students had significantly higher FBG than Hispanic/Latinostudents with frequency of alcohol consumption when adjusted for race/ethnicity (Table 16). Other (individuals identifying with two or more racial groups) had lower FBG than Hispanic/Latino students but was not statistically significant. African American students having lower FBG, and Asian students having higher FBG compared to White students is inconsistent with literature. The literature shows 
disproportionally higher FBG among African American and Hispanic/Latino populations compared to White populations, increasing their risk for developing type II diabetes (Robbins et al., 2001). CDC (2011) estimates over 18\% of non-Hispanic African Americans are diabetic compared to only $10.2 \%$ of non-Hispanic Whites. Likewise, over 40\% of Mexican Americans between 20-39 years of age had a FBG level between 100.9$126.13 \mathrm{mg} / \mathrm{dl}$, the largest proportion of impaired fasting glucose $(\mathrm{p}<0.00001)$ when compared to other races/ethnicities (Cowie et al., 2006). This was significantly higher than only $30.2 \%$ of Whites and $21.3 \%$ of African Americans had FBG in the pre-diabetic and diabetic range (Cowie et al., 2006).

Our study did not show household income to have a significant influence on FBG. However, our research did find individuals in the two lowest household income categories had the highest levels of FBG concentrations. Relatively small sample size may have hampered detection of these differences. We adjusted for household income in Model 2 because research shows an inverse relationship between the prevalence of diabetes and socio-economic status (Connolly et al., 2000; Evans et al., 2000; McKinlay et al., 2010). Low socio-economic status is associated with obesity and limited physical activity and both are strong risk factors for diabetes.

National data shows that alcohol consumption increases with increasing household income and education (Table 2). Our data shows individuals with $\$ 50,000$ or less and individuals with household income between $\$ 87,500$ - $\$ 96,500$ did not consume alcohol on eight or more days within the last 30 days. Nearly equal prevalence (42\%) of students with a $\$ 50,000$ and $\$ 150,000+$ house hold income did not report alcohol consumption, providing no significant trend. 


\section{Discussion of behavioral variables}

In Model 3 we adjusted for behavioral variables; which has been observed to be associated with FBG (Awazawa et al., 2011; Kalupahana, 2012; Gropper et al., 2011; Marieb and Hoehn, 2011). Stress did not show a significant association on FBG, however, stress is observed to elevate FBG (Marieb and Hoehn, 2011). We measured stress by an empirically determined stress test on the survey (PSS) (Cohen, 1983). We may not have observed an association with stress due to the variability of stress throughout the day and academic quarter or due to relatively small sample sizes in each group.

Our study found that physical activity was not associated with FBG levels, which is inconsistent with the literature (Table 13). However, we used ACSM standards to categorize physical activity which may not have been a strong enough marker to determine an association. Additionally, physical activity may not have shown a significant association with FBG due to inaccuracies of self-reported data.

In our study, only four students of the 141 reported smoking. Of these students all four reported drinking at least three days within the last 30 days (Table 10). Model 3 (Table 16) adjusts for smoking and showed no significant difference on FBG. Smoking may increase alcohol consumption since nicotine has been shown to slow gastric emptying therefore, decreasing blood alcohol concentration (Parnell et al., 2006). Decreasing blood alcohol concentration slows the desired effects of alcohol and may cause increased consumption.

Though smoking impacts multiple physiological functions, research has not shown to have a significant association between smoking and FBG. No significant 
differences were found between smokers and non-smokers (Lee, Jung, Park, Rhee, \& Kim, 2012) and no significant differences were found in middle-aged men when comparing fasting glucose levels between nonsmokers, ex-smokers, and current smokers (Janzon, Berntorp, Hanson, Lindell, \& Trell, 1983). In the current study, no conclusions can be drawn, as the sample size of smokers was limiting.

\section{Associated factors and college drinking}

Some hypotheses suggest college enrollment is associated with increased alcohol consumption which may be caused from stress of a new residence or leaving high school, which can stimulate a change in behavior (Wood et al., 2007). Other variables that are associated with college drinking are participation with sororities, fraternities and class schedule (Gfroerer, Greenblatt, \& Wright, 1997; White and Rabiner, 2012; Wood et al., 2007; Wilsnack, Vogeltanz, Wilsnack, \& Harris, 2000; McCabe et al., 2005).

College residency is one of the largest influences of college drinking (Gfroerer et al., 1997; White and Rabiner, 2012), even when adjusted for age, race, and sex. Prevalence of binge drinking is higher among students who live on campus than students who live off campus, and least among students who live off campus with their parents (Gfroerer et al., 1997). Students who move out of their parent's home for the first time can experience anxiety which may influence their decision to turn to alcohol (Schulenberg, 2002).

Other factors have also been shown to strongly influence alcohol consumption in these groups. Class schedule has been associated with influencing alcohol consumption among college students. Wood, Sher, Rutledge (2007), examined students drinking patterns and the 'Thirsty Thursday' phenomenon. It was observed students consumed 
significantly less alcohol Sunday through Wednesday, and Thursday drinking patterns were highly associated with Friday class schedule. Students with Friday class at 8 am or earlier consumed a mean of 1.24 drinks on Thursday night, about half the amount of alcohol compared to students without classes on Fridays with a mean number of drinks of 2.52 drinks ( $\mathrm{p} \leq 0.001)$. Students with Friday classes beginning at noon or later reported drinking a mean of 2.41 drinks on the Thursday before, similar to students without any Friday classes.

Affiliation with fraternities and sororities is also a significant association between alcohol consumption and college enrollment (White and Rabiner, 2012). Involvement in fraternities or sororities has been associated with higher levels of alcohol consumption and binge drinking (McCabe et al., 2005). McCabe et al., (2005) conducted a study in which they followed high school seniors through their first and second years of college. As high school seniors, $47 \%$ of males who anticipated entering a fraternity reported binge drinking in the past two weeks, whereas only $27 \%$ of non-fraternity bound males reported binge drinking $(\mathrm{p}<0.05)$. Following their first year of college, $70 \%$ of fraternity males participated in binge drinking in the past two weeks, whereas $42 \%$ of non-Greek males reported binge drinking $(\mathrm{p}<0.05)$. Members of the Greek system who eventually quit their involvement in fraternities and sororities reported consuming less alcohol after their involvement ended when compared to when they were active members (Schulenberg, 2002; White and Rabiner, 2012). Figure 8 illustrates the average number of times binge drinking was reported in the past two weeks among students who were affiliated with the Greek system, students who were not, and students who joined the Greek system after their first year of college, and students who quit after their second year of college. 
Fraternity members report higher rates of alcohol consumption than sororities (Wilsnack et al., 2000).

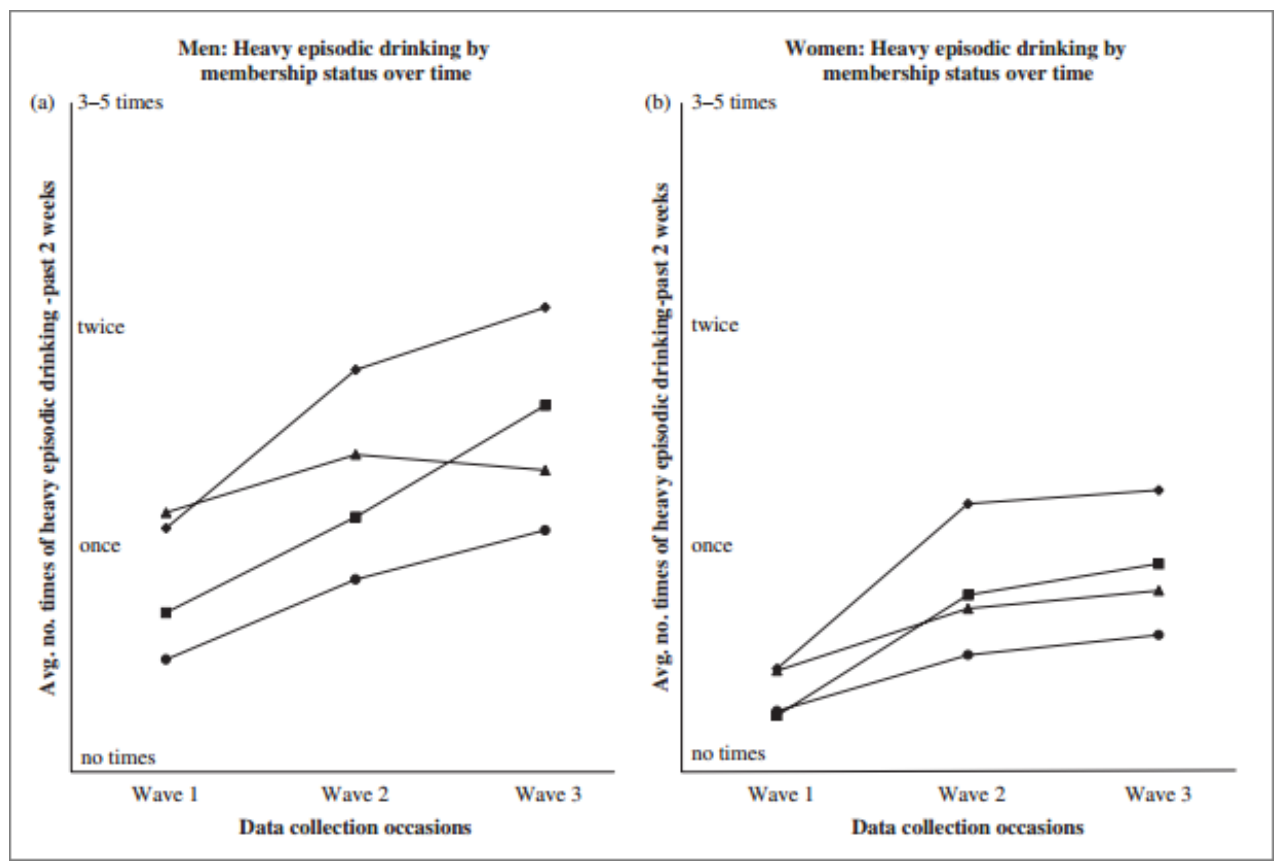

Figure 10. Frequency of heavy episodic drinking in the past two weeks among students by Greek involvement. member, $\bullet$ nonmember, $\boldsymbol{\Delta}$ member at 2 nd year, $\boldsymbol{\square}$ member at 3rd year (McCabe et al., 2005).

Park, Sher \& Krull (2008) found this relationship between alcohol consumption was strongly associated with affiliation with the Greek system regardless of what year in college students participated or quit. Park et al., (2008) found that students affiliated with the Greek system reported higher prevalence of consuming five or more drinks when compared to their prevalence of alcohol consumption when they were a non-member. Students who joined a fraternity or sorority later in their college career reported an increase in frequency of heavy drinking, $(\mathrm{p}=0.002)$. Greek members who quit during their time in college reported a decrease in alcohol consumption $(\mathrm{p}=0.047)$.

Other than the college environment, there are many additional factors suggested to influence alcohol consumption among young adults. Some researchers suggest that 
young adults turn to alcohol as a way to ease the stress of entering adulthood (Schulenberg, 2002), reduce social inhibitions, and boost self-confidence (Ito, Miller, \& Pollock, 1996; White \& Rabiner, 2012). Young men especially may seek alcohol to ease anxiety during sexual maturation and social pressure (White and Rabiner, 2012). The media may even encourage alcohol consumption as a part of a modern and chic lifestyle (Smart, 2007). The anticipation until becoming of legal age may also play a role among young adults (White and Rabiner, 2012). Physiological evidence of brain development and maturation during late teens through the twenties has been observed to play a role with increased risk taking (White \& Rabiner, 2012).

Physiological and psychological development has also been hypothesized to influence alcohol consumption among young adults (Giedd et al., 1999). The limbic system, which includes the amygdala and hippocampus, is responsible for emotions, memory, motivation, and sexual behavior and reaches full maturity during the teenage years. The pre-frontal cortex (PFC) is associated with reasoning, judgment, behavior, and self-control. However the PFC reaches full maturity in the mid-20s, later than the limbic system, and is observed to develop earlier in females than males (White and Rabiner, 2012; Marieb and Hoehn, 2011; Giedd et al., 1999). Therefore, until the PFC reaches maturation, it is thought that behavior is controlled predominately by the limbic system, thus causing impulsive and risky behavior, such as binge drinking (Schulenberg, 2002; White and Rabiner, 2012). Maturation of the PFC takes control by a top down approach, increasing inhibitory control as it develops. 


\section{Review and conclusion}

The mean FBG concentration in the current sample was $85.9 \pm 7.6 \mathrm{mg} / \mathrm{dl}$ and 80.3 $\pm 6.8 \mathrm{mg} / \mathrm{dl}$ for males and females respectively, and were found to be similar compared to national averages. The average FBG levels for young adults between the ages of 18-30 years old were found to be $82.2 \mathrm{mg} / \mathrm{dl} \pm 12.9$ (Duffey Gordon-Larsen, Steffen, Jacobs, \& Popkin, 2010) and $80.5 \mathrm{mg} / \mathrm{dl}$ for adults 20-38 years old (Camhi et al., 2010).

Limitations to this study are the size of our sample, which may have limited our ability to detect significant associations. Though we know there is a significant difference between frequency of alcohol consumption and FBG, we have not determined specifically the range of days of alcohol consumption determines significance. Accuracy of self- reported data is another potential limitation, especially with regard to selfreported height and weight (Spencer, Appleby, Davey, \& Key, 2001). Self-reported data in defining an alcoholic drink and frequency of consumption and binge drinking may also be a limiting factor due to reporting bias (Flanagan et al., 2000). The original cohort of the Heart Health study began with 204 participants, all were contacted, however some students were no longer eligible to participate or no longer interested in the study, decreasing our sample size. The small sample size inhibited our analysis to stratify by sex, which may have provided more insight to associations with behavioral variables.

The definition and measurement of a drink is also highly variable. NIAAA guidelines for moderate drinking is no more than four drinks on any single day and no more than 14 drinks per week, where the CDC labels a frequent drinker consumes 12 or more drinks per year. The inconsistency of what determines a drink is probably partially responsible for the ambiguity of how the public defines a drink, therefore reflecting 
minimal precision and accuracy in self-reported data. NIAAA defines binge drinking as having greater than five drinks within two hours for men and having greater than four drinks within two hours for women. Since this study was a sub-study of the FLASH cohort we were limited to the survey provided by FLASH. Question 24 only asked how many times subjects consumed five or more drinks. Therefore, we could not stratify binge drinking by sex according to NIAAA guidelines. Self-reported data aids in loss of accuracy, and Flanagan et al., (2000) found self-reported alcohol consumption was most likely under reported, which also may have been due to variability of defining a single drink.

Many lab tests are used to determine FBG values as well as diagnose diabetes, therefore, a single instance of abnormally elevated glucose values is not diagnostic (CDC, 2011a). . Multiple measurements of FBG per student subject, or additional test methods such as oral glucose tolerance test, and insulin concentration would aid in more accurate association of alcohol on FBG. Additionally, further research may be interested in the mechanism of adiponectin and resistin hormones.

Thorough research has been conducted analyzing alcohol and both the health benefits and consequences. Research with diabetes has become increasingly more current as diabetes prevalence rises. Inferior comparison of our data to literature was due to the limited resources that have examined fasting blood glucose and alcohol consumption among young adults. Added difficulty with collecting studies from this population may be attributed to the National Library of Medicine recently defining the term 'young adult' as a medical subject heading in articles published after 2008. Additional research with 
this study and the FLASH study can observe associations of college residency, fraternity and sorority affiliations, stress, and sleep patterns among FBG.

Strengths of this study are that it used young adult subjects, an under-represented group in the literature. Additionally, this study measured blood glucose concentrations by fasting blood glucose tests, a test used to help diagnose diabetes in clinics and hospitals. Technicians were trained to aid in accuracy and precision of blood sample collection and measurement. This study also provided campus and community awareness of diabetes, FBG levels, as well as other health variables as part of the Heart Health and FLASH studies and provided participants with educational materials and healthy ranges on fasting blood glucose.

In conclusion, prevalence of diabetes continues to grow, making diabetes a significant economic and public health burden. Identifying health concerns at an earlier age can prevent premature mortality and postpone morbidity. This would decrease public expenditure on health care costs and decrease indirect costs due to work loss and disability. Additionally it would lessen the economic and emotional burden on families aiding to increased quality of life. Studying young adults can help analyze early risk factors for diabetes and pre-diabetes, facilitating public health efforts to stem the rising tide of the diabetes epidemic. FBG is a tool that can help diagnose diabetes, in that lower FBG levels are observed to decrease risk for developing type II diabetes. In summary, we found that moderate frequency of alcohol consumption is found to have an inverse relationship with FBG and excessive drinking can reverse these effects. 


\section{BIBLIOGRAPHY}

Abel, E. L., Kruger, M. L., \& Friedl, J. (1998). How do physicians define "light", "moderate", and "heavy" drinking? Alcoholism-Clinical and Experimental Research, 22(5), 979-984.

Ajani, U. A., Gaziano, J. M., Lotufo, P. A., Liu, S. M., Hennekens, C. H., Buring, J. E., et al. (2000). Alcohol consumption and risk of coronary heart disease by diabetes status. Circulation, 102(5), 500-505.

Athyros, V. G., Liberopoulos, E. N., Mikhailidis, D. P., Papageorgiou, A. A., Ganotakis, E. S., Tziomalos, K., et al. (2008). Association of drinking pattern and alcohol beverage type with the prevalence of metabolic syndrome, diabetes, coronary heart disease, stroke, and peripheral arterial disease in a Mediterranean cohort. Angiology, 58(6), 689-697.

Awazawa, M., Ueki, K., Inabe, K., Yamauchi, T., Kubota, N., Kaneko, K., et al. (2011). Adiponectin Enhances Insulin Sensitivity by Increasing Hepatic IRS2 Expression via a Macrophage-Derived IL-6-Dependent Pathway. Cell Metabolism, 13(4), 401-412.

Baliunas, D. O., Taylor, B. J., Irving, H., Roerecke, M., Patra, J., Mohapatra, S., et al. (2009). Alcohol as a Risk Factor for Type 2 Diabetes A systematic review and meta-analysis. Diabetes Care, (11), 2123-32.

Beulens, J. W. J., van Loon, L. J. C., Kok, F. J., Pelsers, M., Bobbert, T., Spranger, J., et al. (2007). The effect of moderate alcohol consumption on adiponectin oligomers and muscle oxidative capacity: a human intervention study.

Diabetologia, 50(7), 1388-1392. 
Boffetta, P., \& Garfinkel, L. (1990). Alcohol drinking and mortality among men enrolled in an American Cancer Society prospective study. Epidemiology (Cambridge, Mass.), (5), 342-348.

California Polytechnic State University (2012). Quick Facts. Retrieved from http://www.calpolynews.calpoly.edu/quickfacts.html

Camhi, S. M., Katzmarzyk, P. T., Broyles, S., Srinivasan, S. R., Chen, W., Bouchard, C., et al. (2010). Predicting Adult Body Mass Index-Specific Metabolic Risk From Childhood. Metabolic Syndrome and Related Disorders, 8(2), 165-172.

CDC Healthy People 2010; National Center for Health Statistics Healthy People 2010 Stat Notes U.S. Dept. of Health and Human Services, Centers for Disease Control and Prevention, National Center for Health Statistics, (2001-2011). Retrieved from http://www.cdc.gov/diabetes/surveillance/index.htm Centers for Disease Control and Prevention. National diabetes fact sheet: national estimates and general information on diabetes and prediabetes in the United States, 2011. (2011a). Atlanta, GA: U.S. Department of Health and Human Services, Centers for Disease Control and Prevention. Retrieved from http://www.cdc.gov/diabetes/pubs/pdf/ndfs_2011.pdf

Centers for Disease Control and Prevention, (2011b). Division of Cancer Prevention and Control, National Center for Chronic Disease Prevention and Health Promotion. Retrieved from http://www.cdc.gov/cancer/dcpc/data/ 
Cohen,S. Kamarck T., \& Mermelstein, R. (1983). A Global measure of perceived stress. Journal of Health and Social Behavior. (24)4: 385-396.

Connolly, V., Unwin, N., Sherriff, P., Bilous, R., \& Kelly, W. (2000). Diabetes prevalence and socioeconomic status: a population based study showing increased prevalence of type 2 diabetes mellitus in deprived areas. Journal of Epidemiology and Community Health, 54(3), 173-177.

Courtenay H. (2002). Behavioral factors associated with disease, injury, and death among men: evidence and implications for prevention will. Journal of Mens Studies, Fall 9(1), 81-142.

Cowie, C. C., Engelgau, M. M., Rust, K. F., Saydah, S. H., Byrd-Holt, D. D., Williams, D. E., et al. (2006). Prevalence of diabetes and impaired fasting glucose in adults in the US population - National Health and Nutrition Examination Survey 1999-2002. Diabetes Care, 29(6), 1263-1268.

Cowie, C. C., Rust, K. F., Ford, E. S., Eberhardt, M. S., Byrd-Holt, D. D., Li, C., et al. (2011). Full accounting of diabetes and pre-diabetes in the U.S. population in 1988-1994 and 2005-2006 Diabetes Care, 32(2), 287-294.

Danaei, G., Finucane, M. M., Lu, Y., Singh, G. M., Cowan, M. J., Paciorek, C. J., et al. (2011). National, regional, and global trends in fasting plasma glucose and diabetes prevalence since 1980: systematic analysis of health examination surveys and epidemiological studies with 370 country-years and 2.7 million participants. Lancet, 2;378 (9785), 31-40.

Dasgupta, Amitava. (2012). The Science of Drinking: How Alcohol Affects Your Body and Mind. Lanham, MD: Rowman \& Littlefield. 
Davies, M. J., Baer, D. J., Judd, J. T., Brown, E. D., Campbell, W. S., \& Taylor, P. R. (2002). Effects of moderate alcohol intake on fasting insulin and glucose concentrations and insulin sensitivity in postmenopausal women - A randomized controlled trial. Journal of the American Medical Association, $15 ; 287(19), 2559-62$.

Duffey, K., Gordon-Larsen, P., Steffen, L. M., Jacobs, D.R. \& Popkin, B. M. (2010), Drinking caloric beverages increases the risk of adverse cardiometabolic outcomes in the coronary artery risk development in young adults. American Journal of Clinical Nutrition, 92:954-959.

Dunstan, D. W., Zimmet, P. Z., Welborn, T. A., de Courten, M. P., Cameron, A. J., Sicree, R. A., et al. (2002). The rising prevalence of diabetes and impaired glucose tolerance - The Australian diabetes, obesity and lifestyle study. Diabetes Care, 25(5), 829-834.

Evans, J. M. M., Newton, R. W., Ruta, D. A., MacDonald, T. M., \& Morris, A. D. (2000). Socio-economic status, obesity and prevalence of Type 1 and Type 2 diabetes mellitus. Diabetic Medicine, 17(6), 478-480.

Facchini, F., Chen, Y. D. I., \& Reaven, G. M. (1994). Light -to-moderate alcohol intake is associated with enhance insulin sensitivity. Diabetes Care, 17(2), 115-119.

Flanagan, D. E. H., Moore, V. M., Godsland, I. F., Cockington, R. A., Robinson, J. S., \& Phillips, D. I. (2000). Alcohol consumption and insulin resistance in young adults. European Journal of Clinical Investigation, 30(4), 297-301. 
Gfroerer, J. C., Greenblatt, J. C., \& Wright, D. A. (1997). Substance use in the US college-age population: Differences according to educational status and living arrangement. American Journal of Public Health, 87(1), 62-65.

Giedd, J. N., Blumenthal, J., Jeffries, N. O., Castellanos, F. X., Liu, H., Zijdenbos, A., et al. (1999). Brain development during childhood and adolescence: a longitudinal MRI study. Nature Neuroscience, 2(10), 861-863.

Gropper, S. A. S., Groff J. L., \& Smith, J. L. (2009). Advanced Nutrition and Human Metabolism. Belmont, CA: Wadsworth, Cengage Learning.

Haskell, W. L., Lee, I. M., Pate, R. R., Powell, K. E., Blair, S. N., Franklin, B. A., et al. (2007). Physical activity and public health - Updated recommendation for adults from the American college of sports medicine and the American heart association. Circulation, 116(9), 1081-1093.

Heidenreich, P. A., Trogdon, J. G., Khavjou, O. A., Butler, J., Dracup, K., Ezekowitz, M. D., et al. (2011). Forecasting the Future of Cardiovascular Disease in the United States: A policy statement from the American Heart Association.

Circulation, 123(8), 933-944.

Hogan, P., Dall, T., Nikolov, P., \& American Diabetes, A. (2003). Economic costs of diabetes in the US in 2002. Diabetes care, 26(3), 917-932.

Ito, T. A., Miller, N., \& Pollock, V. E. (1996). Alcohol and aggression: A metaanalysis on the moderating effects of inhibitory cues, triggering events, and self-focused attention. Psychological Bulletin, 120(1), 60-82. 
Janzon, L., Berntorp, K., Hanson, M., Lindell, S. F., \& Trell, E. (1983). Glucosetolerance and smoking- a population study of oral and intravenous glucosetolerance tests in middle- aged men. Diabetologia, 25(2), 86-88.

Johnston, L. D., O’Malley, P. M., Bachman, J.G. \& Schulenberg, J. E. (2010), Monitory the future national survey results on drug use, 1975-2009: Vol. I Secondary school students. Bethesda, MD: National Institute on Drug Abuse.

Joosten, M. M., Beulens, J. W. J., Kersten, S., \& Hendriks, H. F. J. (2008). Moderate alcohol consumption increases insulin sensitivity and ADIPOQ expression in postmenopausal women: a randomised, crossover trial. Diabetologia, 51(8), 1375-1381.

Juonala, M., Viikari, J. S. A., Kahonen, M., Taittonen, L., Laitinen, T., HutriKahonen, N., et al. (2010). Life-time risk factors and progression of carotid atherosclerosis in young adults: the Cardiovascular Risk in Young Finns study. European Heart Journal, 31(14), 1745-1751.

Kalupahana, N. S., Moustaid-Moussa, N., \& Claycombe, K. J. (2012). Immunity as a link between obesity and insulin resistance. Molecular Aspects of Medicine, 33(1), 26-34.

Koppes, L. L. J., Dekker, J. M., Hendriks, H. F. J., Bouter, L. M., \& Heine, R. J. (2005). Moderate alcohol consumption lowers the risk of type 2 diabetes - A meta-analysis of prospective observational studies. Diabetes Care, 28(3), 719-725.

Lee, W. Y., Jung, C. H., Park, J. S., Rhee, E. J., \& Kim, S. W. (2005). Effects of smoking, alcohol, exercise, education, and family history on the metabolic 
syndrome as defined by the ATP III. Diabetes Research and Clinical Practice, 67(1), 70-77.

Liese, A. D., D'Agostino, R. B., Jr., Hamman, R. F., Kilgo, P. D., Lawrence, J. M., Liu, L. L., et al. (2006). The burden of diabetes mellitus among US youth: Prevalence estimates from the SEARCH for Diabetes in Youth Study. Pediatrics, 118(4), 1510-1518.

Marieb, Elaine N., \& Katja N. Hoehn. (2011). Anatomy and Physiology with Interactive Physiology. San Francisco, CA: Benjamin Cummings.

Maxwell, S., Cruickshank, A., \& Thorpe, G. (1994). Red wine and antioxidant activity in serum. Lancet, 344(8916), 193-194.

McCabe, S. E., Schulenberg, J. E., Johnston, L. D., O'Malley, P. M., Bachman, J. G., $\&$ Kloska, D. D. (2005). Selection and socialization effects of fraternities and sororities on US college student substance use: a multi-cohort national longitudinal study. Addiction, 100(4), 512-524.

McKinlay J, Link C, Piccolo R, Meigs J, Marceau L. (2010).The social construction of race/ethnic disparities in diabetes-A case of misplaced concreteness New England Journal of Medicine 2010(6)1.

Miller, M., Stone, N. J., Ballantyne, C., Bittner, V., Criqui, M. H., Ginsberg, H. N., et al. (2011). Triglycerides and Cardiovascular Disease A Scientific Statement From the American Heart Association. Circulation, 123(20), 2292-2333.

Mirsky, S, \& Heilman, J. R. (2006). Diabetes Survival Guide: Understanding the Facts about Diagnosis, Treatment, and Prevention. New York, NY: Ballantine. 
Mokdad, A. H., Ford, E. S., Bowman, B. A., Dietz, W. H., Vinicor, F., Bales, V. S., et al. (2003). Prevalence of obesity, diabetes, and obesity-related health risk factors, 2001. Journal of the American Medical Association, 289(1), 76-79.

Nathan, D. M., Davidson, M. B., DeFronzo, R. A., Heine, R. J., Henry, R. R., Pratley, R., et al. (2007). Impaired fasting glucose and impaired glucose tolerance Implications for care. Diabetes Care, 30(3), 753-759.

National Institute of Health, National Heart Lung, and Blood Institute. (2013). Retrieved from http://nhlbisupport.com/bmi/

Ogden, C. L., Fryar, C. D., Carroll, M. D., \& Flegal, K. M. (2004). Mean body weight, height, and body mass index, United States 1960-2002. Vital and Health Statistics. (347), 1-17.

Park, A., Sher, K. J., \& Krull, J. L. (2008). Risky drinking in college changes as fraternity/sorority affiliation changes: A person-environment perspective. Psychology of Addictive Behaviors, 22(2), 219-229.

Parnell, S. E., West, J. R., \& Chen, W.-J. A. (2006). Nicotine decreases blood alcohol concentrations in adult rats: A phenomenon potentially related to gastric function. Alcoholism-Clinical and Experimental Research, 30(8), 1408-1413.

Renaud, S., \& Delorgeril, M. (1992). Wine, alcohol, platelets, and the French paradox for coronary heart-disease. Lancet, 339, 1523-1526.

Robbins, J. M., Vaccarino, V., Zhang, H. P., \& Kasl, S. V. (2001). Socioeconomic status and type 2 diabetes in African American and non-Hispanic White women and men: Evidence from the Third National Health and Nutrition Examination Survey. American Journal of Public Health, 91(1), 76-83. 
Rosenthal, M. \& Glew, R. (2009). Medical Biochemistry: Human Metabolism in Health and Disease. Hoboken, NJ: John Wiley \& Sons.

Schulenberg J, Maggs J. (2002). A developmental perspective on alcohol use and heavy drinking during adolescence and the transition to young adulthood. Stud. Alcohol, 14:54-70.

Scott, L. J., Bonnycastle, L. L., Willer, C. J., Sprau, A. G., Jackson, A. U., Narisu, N., et al. (2006). Association of transcription factor 7-like 2 (TCF7L2) variants with type 2 diabetes in a Finnish sample. Diabetes, 55(9), 2649-53.

Sierksma, A., Patel, H., Ouchi, N., Kihara, S., Funahashi, T., Heine, R., et al. (2004). Effect of moderate alcohol consumption on adiponectin, tumor necrosis factor-alpha, and insulin sensitivity. Diabetes Care, 58(3):387-392.

Smart, L. (2007). Alcohol and Human Health. Oxford: Oxford University Press.

Spencer, E. A., Appleby, P. N., Davey, G. K., \& Key, T. J. (2001). Validity of selfreported height and weight in 4808 EPIC-Oxford participants. Public Health Nutrition, 5(4), 561-565.

Substance Abuse and Mental Health Services Administration. (2012). Results from the 2010 National Survey on Drug Use and Health: Mental Health Findings, NSDUH Series H-42, HHS Publication No. (SMA) 11-4667, Rockville, MD: Substance Abuse and Mental Health Services Administration.

U.S. Census Bureau, Population Division, Fertility \& Family Statistics Branch. (2004). Current Population Survey: Definitions and explanations. Retrieved from 
Venkat, Narayan KM, Boyle JP, Thompson TJ, Sorensen S, Williamson D. (2003). Lifetime risk for developing diabetes mellitus. Journal of the American Medical Association, 290, 1888-1890.

Wannamethee, S. G., Camargo, C. A., Manson, J. A. E., Willett, W. C., \& Rimm, E. B. (2003). Alcohol drinking patterns and risk of type 2 diabetes mellitus among younger women. Archives of Internal Medicine, 163(11), 1329-1336.

Watkins, T. R. (Eds.). (1997). Wine: Nutritional and Therapeutic Benefits. Washington, DC: American Chemical Society.

White, H. R. and Rabiner, D. L. (2012). College Drinking and Drug Use. New York, NY: Guilford.

Wild, S., Roglic, G., Green, A., Sicree, R., \& King, H. (2004). Global prevalence of diabetes - Estimates for the year 2000 and projections for 2030. Diabetes Care, 27(5), 1047-1053.

Wildman, R. E. C. and Miller, B. S. (2004). Sports and Fitness Nutrition. Belmont, CA: Thomson/Wadsworth.

Wilsnack, R. W., Vogeltanz, N. D., Wilsnack, S. C., \& Harris, T. R. (2000). Gender differences in alcohol consumption and adverse drinking consequences: cross-cultural patterns. Addiction, 95(2), 251-265.

Wood, P. K., Sher, K. J., \& Rutledge, P. C. (2007). College student alcohol consumption, day of the week, and class schedule. Alcoholism-Clinical and Experimental Research, 31(7), 1195-1207.

Yokota, T., Oritani, K., Takahashi, I., Ishikawa, J., Matsuyama, A., Ouchi, N., et al. (2000). Adiponectin, a new member of the family of soluble defense 
collagens, negatively regulates the growth of myelomonocytic progenitors and the functions of macrophages. Blood, 96(5), 1723-32.

Zhang, Y., Dall, T. M., Mann, S. E., Chen, Y., Martin, J., Moore, V., et al. (2009). The economic costs of undiagnosed diabetes. Population Health Management, 12(2), 95-101. 